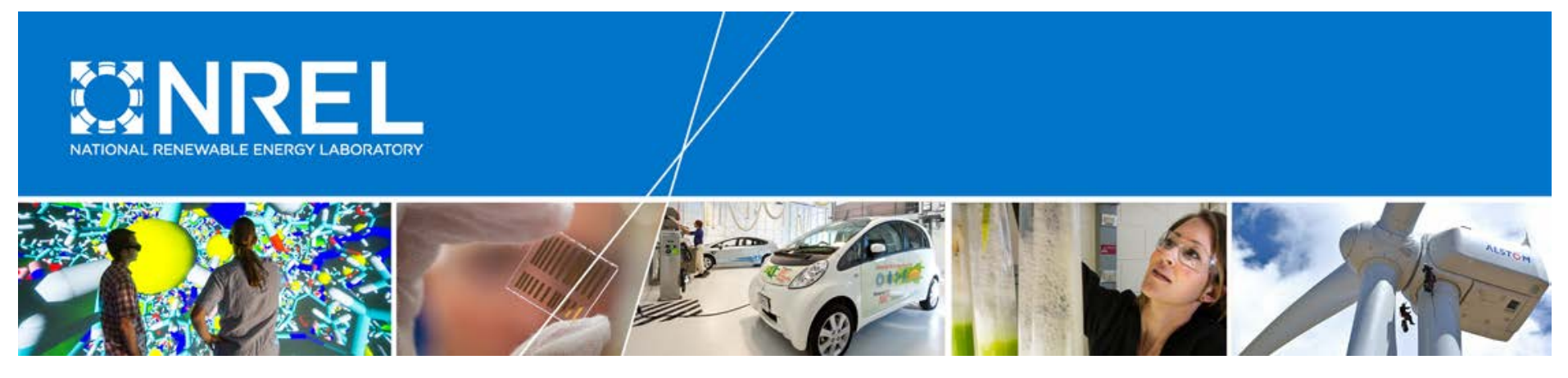

\title{
Electrification \& Decarbonization: Exploring U.S. Energy Use and Greenhouse Gas Emissions in Scenarios with Widespread Electrification and Power Sector Decarbonization
}

Daniel Steinberg, Dave Bielen, Josh Eichman, Kelly Eurek, Jeff Logan, Trieu Mai, Colin McMillan, Andrew Parker, Laura Vimmerstedt, and Eric Wilson National Renewable Energy Laboratory

NREL is a national laboratory of the U.S. Department of Energy Office of Energy Efficiency \& Renewable Energy Operated by the Alliance for Sustainable Energy, LLC

This report is available at no cost from the National Renewable Energy Laboratory (NREL) at www.nrel.gov/publications.

Technical Report

NREL/TP-6A20-68214

July 2017 


\section{Electrification \& Decarbonization: Exploring U.S. Energy Use and Greenhouse Gas Emissions in Scenarios with Widespread Electrification and Power Sector Decarbonization}

Daniel Steinberg, Dave Bielen, Josh Eichman, Kelly Eurek, Jeff Logan, Trieu Mai, Colin McMillan, Andrew Parker, Laura Vimmerstedt, and Eric Wilson National Renewable Energy Laboratory

Prepared under Task No. EP21.0205

NREL is a national laboratory of the U.S. Department of Energy Office of Energy Efficiency \& Renewable Energy Operated by the Alliance for Sustainable Energy, LLC

This report is available at no cost from the National Renewable Energy Laboratory (NREL) at www.nrel.gov/publications.

National Renewable Energy Laboratory 15013 Denver West Parkway Golden, CO 80401

303-275-3000 • www.nrel.gov
Technical Report

NREL/TP-6A20-68214

July 2017

Contract No. DE-AC36-08GO28308 


\section{NOTICE}

This report was prepared as an account of work sponsored by an agency of the United States government. Neither the United States government nor any agency thereof, nor any of their employees, makes any warranty, express or implied, or assumes any legal liability or responsibility for the accuracy, completeness, or usefulness of any information, apparatus, product, or process disclosed, or represents that its use would not infringe privately owned rights. Reference herein to any specific commercial product, process, or service by trade name, trademark, manufacturer, or otherwise does not necessarily constitute or imply its endorsement, recommendation, or favoring by the United States government or any agency thereof. The views and opinions of authors expressed herein do not necessarily state or reflect those of the United States government or any agency thereof.

This report is available at no cost from the National Renewable Energy Laboratory (NREL) at www.nrel.gov/publications.

Available electronically at SciTech Connect http:/www.osti.gov/scitech

Available for a processing fee to U.S. Department of Energy and its contractors, in paper, from:

U.S. Department of Energy

Office of Scientific and Technical Information

P.O. Box 62

Oak Ridge, TN 37831-0062

OSTI http://www.osti.gov

Phone: 865.576.8401

Fax: 865.576.5728

Email: reports@osti.gov

Available for sale to the public, in paper, from:

U.S. Department of Commerce

National Technical Information Service

5301 Shawnee Road

Alexandria, VA 22312

NTIS http://www.ntis.gov

Phone: 800.553 .6847 or 703.605 .6000

Fax: 703.605.6900

Email: orders@ntis.gov 


\section{Acknowledgements}

We would like to thank the following individuals for their thoughtful reviews, comments, and suggestions: David Mooney, Robin Newmark, Gian Porro, Mary Lukkonen, and Karin Haas of the National Renewable Energy Laboratory; Max Wei of the Lawrence Berkeley National Laboratory; Ryan Jones of Evolved Energy; Carla Frisch, Sarah Garman, and Erin Boyd of the Department of Energy's (DOE's) Office of Energy Policy and Systems Analysis; Steve Capanna, Paul Donohoo-Vallett, Kara Podkaminer, Jack Mayernik, John Stevens, Rachel Nealer, Jacob Ward, and David Gohlke of DOE's Office of Energy Efficiency and Renewable Energy. We would also like to thank DOE's Office of Energy Policy and Systems Analysis for primary funding support for this analysis. In particular, we are grateful to Carla Frisch for her support of this study. This research was funded in 2016 by the U.S. Department of Energy under contract number DE-AC36-08GO28308. Any errors or omissions are the sole responsibility of the authors. 


\section{Preface}

This report, funded by the U.S. Department of Energy's Office of Energy Policy and Systems Analysis, describes an initial analysis exploring the potential implications of widespread electrification of energy services in the buildings, transportation, and industrial sectors on the future evolution of the U.S. electricity system. Given its exploratory nature, the analysis considers only a limited set of electrification, efficiency, and power sector decarbonization scenarios; in addition, estimates of the electrification potential of each end-use sectorbuildings, industry, and transport - are based on a relatively aggregated analysis of end-use service and fuel demands by sector and state and, therefore, do not consider explicit technologies, adoption patterns, or other detailed issues that could ultimately affect results.

Ongoing and potential future work is designed to apply a suite of higher-fidelity sector-specific models to address some of the same questions as posed in the exploratory analysis. This followon work will use a detailed accounting framework of energy use in all sectors, explore a larger number of electrification technology options and scenarios, employ high-resolution sectorspecific bottom-up engineering models to project future electricity consumption patterns, and conduct detailed electricity system production cost modeling.

This study contributes to a considerable body of work at the National Renewable Energy Laboratory that explores the potential for clean energy and efficiency technologies, along with related research and development, demonstration, and deployment activities and policies, to affect the future evolution and operation of the U.S. electricity system. 


\section{List of Acronyms}

\begin{tabular}{|c|c|}
\hline $\mathrm{AEO}$ & Annual Energy Outlook \\
\hline ANL & Argonne National Laboratory \\
\hline ASHRAE & $\begin{array}{l}\text { American Society of Heating, Refrigerating and } \\
\text { Air-Conditioning Engineers }\end{array}$ \\
\hline $\mathrm{BEV}$ & battery electric vehicle \\
\hline $\mathrm{BF}$ & blast furnace \\
\hline BLAST-V & $\begin{array}{l}\text { Battery Lifetime Analysis and Simulation Tool for } \\
\text { Vehicles }\end{array}$ \\
\hline $\mathrm{BOF}$ & basic oxygen furnace \\
\hline CBECS & Commercial Buildings Energy Consumption Survey \\
\hline CCUS & carbon capture, utilization, and sequestration \\
\hline $\mathrm{CH}_{4}$ & methane \\
\hline $\mathrm{CO}_{2}$ & carbon dioxide \\
\hline $\mathrm{CO}_{2}-\mathrm{e}$ & carbon dioxide equivalent \\
\hline $\mathrm{CPP}$ & Clean Power Plan \\
\hline CSP & concentrating solar power \\
\hline DOE & U.S. Department of Energy \\
\hline EIA & U.S. Energy Information Administration \\
\hline EPA & U.S. Environmental Protection Agency \\
\hline EPRI & Electric Power Research Institute \\
\hline EPSA & Office of Energy Policy and System Analysis \\
\hline $\mathrm{EV}$ & electric vehicle \\
\hline $\mathrm{FCV}$ & fuel cell vehicle \\
\hline GHG & greenhouse gas \\
\hline GHGRP & EPA's Greenhouse Gas Reporting Program \\
\hline GVWR & gross vehicle weight rating \\
\hline $\mathrm{HDV}$ & heavy-duty vehicle \\
\hline $\mathrm{HEV}$ & hybrid electric vehicle \\
\hline $\mathrm{HFC}$ & fluorine-containing substance \\
\hline LDV & light-duty vehicle \\
\hline MDV & medium-duty vehicle \\
\hline $\mathrm{M} / \mathrm{HDV}$ & medium- and heavy-duty vehicles \\
\hline Mt & metric ton \\
\hline $\mathrm{N}_{2} \mathrm{O}$ & nitrous oxide \\
\hline NEMS & National Energy Modeling System \\
\hline NEVA & National Economic Value Assessment \\
\hline NGCC & natural gas combined cycle \\
\hline PHEV & plug-in hybrid electric vehicle \\
\hline PV & solar photovoltaics \\
\hline RECS & Residential Energy Consumption Survey \\
\hline ReEDS & Regional Energy Deployment System \\
\hline REF & Renewable Electricity Futures \\
\hline SEDS & State Energy Data System \\
\hline SERA & Scenario Evaluation and Regionalization Analysis \\
\hline $\mathrm{TEF}$ & Transportation Energy Futures \\
\hline
\end{tabular}




\section{Executive Summary}

Electrification of end-use services in the transportation, buildings, and industrial sectors coupled with decarbonization of electricity generation has been identified as one of the key pathways to achieving a low-carbon future in the United States. By lowering the carbon intensity of the electricity generation and substituting electricity for higher-emissions fossil fuels in end-use sectors, significant reductions in carbon dioxide emissions can be achieved. This report describes a preliminary analysis that examines the potential impacts of widespread electrification on the U.S. energy sector. We develop a set of exploratory scenarios under which electrification is aggressively pursued across all end-use sectors and examine the impacts of achieving these electrification levels on electricity load patterns, total fossil energy consumption, carbon dioxide emissions, and the evolution of the U.S. power system.

Using business-as-usual projections of end-use fuel and service demands as a starting point, we developed scenarios of electrification for each end-use sector based on exogenously defined rates of electrification and efficiency improvements for each end-use service. We then employ a highly detailed power sector model to study the impacts of electrification on the U.S. power sector and on greenhouse gas (GHG) emissions. We simulate the evolution of the power system both with and without an assumed power sector cap on GHG emissions of $83 \%$ below the 2005 level by 2050 .

Under the scenarios explored, widespread electrification of end-use services across the transportation, buildings, and industrial sectors leads to a doubling of electricity consumption by 2050 , but moderate improvements in the energy efficiency of end-use devices can substantially limit the growth in load. Furthermore, despite driving large increases in total load, temporal flexibility in some end uses, such as hydrogen production for vehicles and electric vehicle charging (as assumed in this study), can offset the increased peak demand in other end uses (e.g., buildings) such that electrification has the potential to reduce variability or "peaky-ness" of load, which can aid in the integration of new resources - particularly variable renewable resources.

Results from power sector modeling demonstrate that incremental load associated with electrification is predominantly met with generation from new wind, solar, and natural gas combined cycle capacity and, to a lesser extent, with increased generation from existing natural gas combined cycle capacity. However, when power sector emissions are capped at $83 \%$ below 2005 levels by 2050, carbon capture, utilization, and sequestration (CCUS) technologies also play a significant role in meeting demand.

Aggregating effects to the economy level, we find that electrification of end uses, when coupled with power sector decarbonization, has the potential to substantially reduce economy-wide emissions of carbon dioxide $\left(\mathrm{CO}_{2}\right)$ associated with fossil fuel combustion. Specifically, we find that, by 2050, electrification and simultaneous power sector decarbonization can achieve reductions of nearly $74 \%$ below the 2005 level of economy-wide fossil fuel combustion emissions. Furthermore, even in the absence of policies to lower the emissions intensity of electricity generation, electrification alone can have a significant impact on GHG emissions. We find that electrification, in the absence of any additional power sector carbon policy, can result in $41 \%$ reductions (below 2005 level) in economy-wide fossil fuel combustion emissions. 
Despite this significant potential to reduce emissions, the level of electrification and the degree of decarbonization explored in these scenarios are not, in isolation, sufficient to achieve reductions in economy-wide GHG emissions of $83 \%$ below the 2005 level. Thus, pathways to achieving deep reductions in GHG emissions will necessarily involve additional strategies for reduction, but electrification and electricity decarbonization will play a large and important role in achieving a low-carbon future. Future work is needed to understand other potential implications of widespread electrification and the challenges and risks associated with electrification. 


\section{Table of Contents}

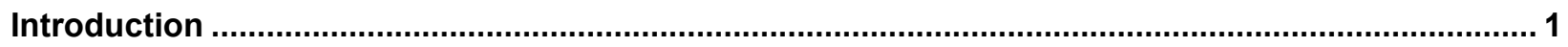

Background

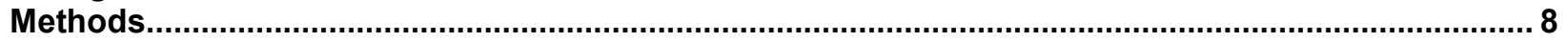

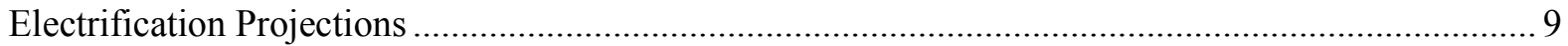

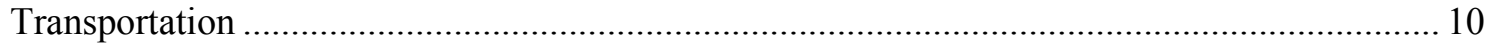

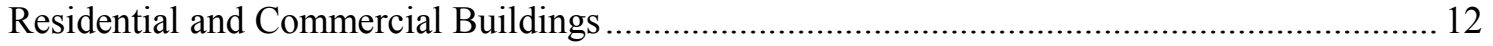

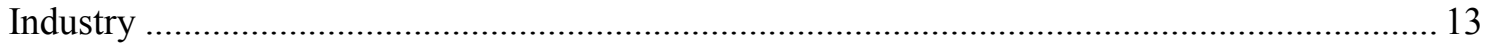

Generation and Transmission Expansion Simulation.................................................................... 15

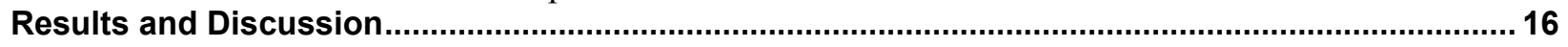

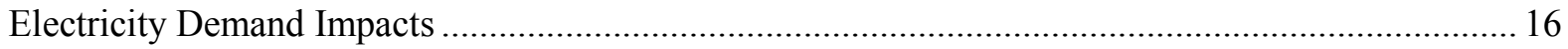

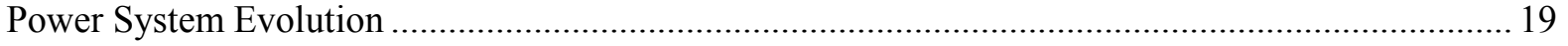

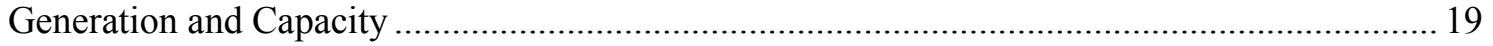

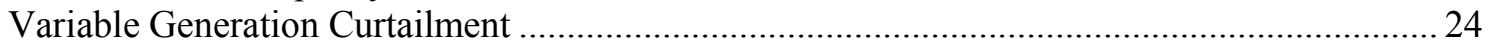

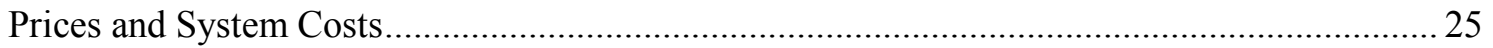

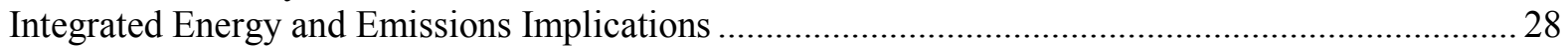

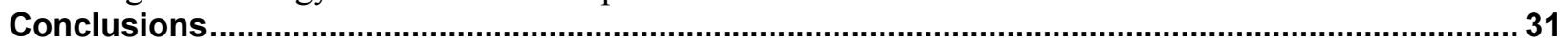

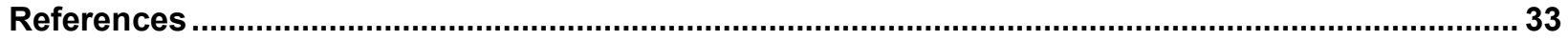

Appendix. Detailed Methods for Electrification Potential Estimates and Development of the Hourly

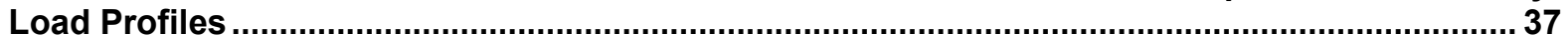

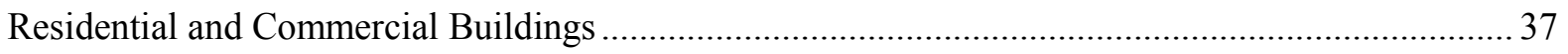

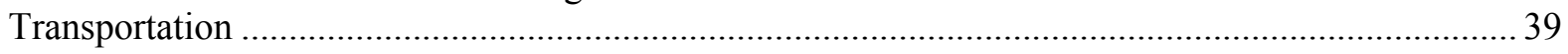

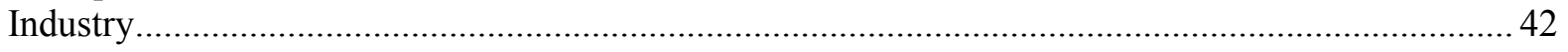




\section{List of Figures}

Figure 1. 2014 GHG emissions from fossil fuel combustion by sector (left) and by sector with emissions associated with electricity generation distributed to end-use sectors (right) ....................... 3

Figure 2. 2014 GHG emissions from fossil fuel combustion in the transportation sector .......................... 5

Figure 3. Industrial energy consumption as a fuel by end-use service and energy type (2010); data exclude energy consumption as a non-fuel (feedstock)............................................................ 6

Figure 4. Final energy use in residential buildings by source and application-2009 residential

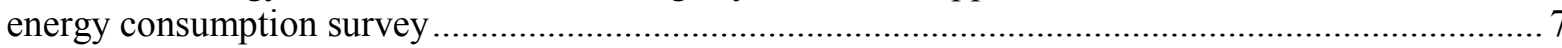

Figure 5. Final energy use in commercial buildings by source and application-2012 commercial

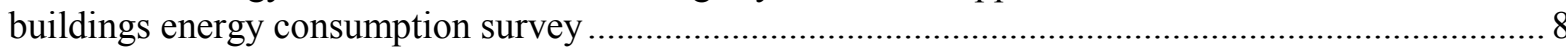

Figure 6. Total market penetrations of vehicle types from 2010 to 2050 for light-duty, and medium-

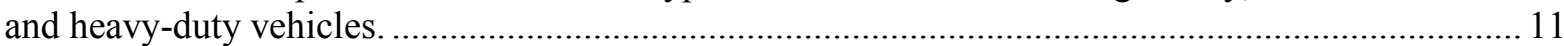

Figure 7. Reference and incremental electricity consumption from electrification by sector, 2016-2050

Figure 8. Peak-to-average demand ratio for the Reference, HighElec, and HighComb scenarios.

Figure 9. Generation (top) and capacity (bottom) mix over time for the Baseline scenario (left) and the difference between the Baseline-HighElec scenario and the Baseline scenario (right)................. 20

Figure 10. Generation (top) and capacity (bottom) mix over time for the Baseline-HighElec scenario (left) and the difference between the Decarb-HighElec scenario and the Baseline-HighElec scenario (right)

Figure 11. Generation (top) and capacity (bottom) mix over time for the Baseline scenario (left) and the difference between the Baseline-HighComb scenario and the Baseline scenario (right) ........ 23

Figure 12. Relationship between variable renewable resource penetration and average curtailment......... 24

Figure 13. Marginal (top) and average (bottom) electricity prices by decade for all scenarios.................26

Figure 14. Carbon dioxide allowance prices over time for all scenarios ...............................................2 27

Figure 15. Projected carbon emissions from combustion of fossil fuels across all sectors and end

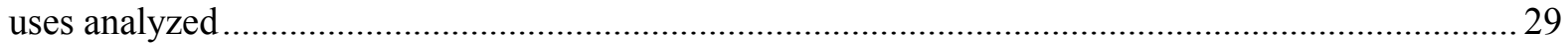

Figure A-1. Locations of the representative households simulated using the EnergyPlus model .............. 38

\section{List of Tables}

Table 1. Description of the Electrification Scenarios

Table 2. Annual Average Incremental Efficiency Improvement in Electric End-Use Devices from 2017-2050 Assumed in the High-Efficiency Case.

Table 3. Industrial End Uses and Electric Technologies Selected for Analysis ...................................... 14

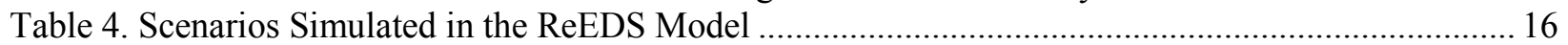

Table A-1. Residential and Commercial End-Use Services Represented in the NEMS Model ${ }^{\mathrm{a}}$.................. 37

Table A-2. Assumed Growth Rates of Electrotechnologies in Their Applicable Industries and by End Use 


\section{Introduction}

Opportunities and pathways to achieving deep reductions $(60 \%-80 \%)$ in U.S. greenhouse gas (GHG) emissions have been explored in a number of studies (Wei et al. 2013; Williams et al. 2014; EOP/CEQ 2016; Clarke et al. 2014). These analyses demonstrate that large emissions reductions are achievable through a broad range of opportunities, including increased end-use energy efficiency, decarbonization of electricity supply, increased reliance on low- or zerocarbon energy sources, use of carbon capture, utilization, and sequestration (CCUS) technologies, and substitution of traditional fossil-fuel-based industrial feedstocks with low- or zero-carbon alternatives. In particular, electrification of technologies across end-use sectors (transportation, residential and commercial buildings, and industry) coupled with decarbonization of the power sector has been identified as one of the key components to achieving deep cuts in GHG emissions (Williams et al. 2014) due to the low cost and wide set of options for reducing power sector emissions. Assuming rapidly decreasing carbon emissions intensity of electricity generation and replacing fossil-fueled technologies with electric technologies can lead to significant reductions in GHG emissions related to direct fuel combustion.

The analysis presented in this report takes a closer look at this high-electrification pathway in order to gain insights on:

1. The potential to reduce carbon dioxide $\left(\mathrm{CO}_{2}\right)$ emissions through coupled decarbonization of the power sector and widespread electrification of end-use processes ${ }^{1}$ across the U.S. economy

2. How the power sector may evolve to meet the rapidly growing demand for electricity while simultaneously reducing power sector GHG emissions

3. How increased end-use efficiency can mitigate the necessary investment in the power sector to meet the growing electricity demand.

We explore the potential for electrification and associated emissions reductions through an analysis of fuel and end-use service consumption in each of the end-use demand sectors: transportation, buildings, and industry. Subsequently, using the results from the sectoral potential analyses as inputs, we employ a highly regional and temporally detailed model of the power sector using the Regional Energy Deployment System (ReEDS) ${ }^{2}$ to simulate the buildout and operation of the electric system under this high-demand future. We explore a scenario in which electrification is coupled with additional power sector emissions limits and one in which only currently existing policies are maintained, as well as scenarios in which end-use efficiency improvements decrease the electricity intensity of end uses.

We demonstrate that there is a large potential to reduce economy-wide fossil fuel combustion emissions through electrification of end-use services, particularly when electrification is coupled

\footnotetext{
${ }^{1}$ End-use processes refer to the conversion of energy into an energy service, such as converting gasoline into mobility or transportation or electricity into air conditioning.

${ }^{2}$ More information about the ReEDS model can be found in the documentation (Eurek et al. 2016; Short et al. 2011) as well as in numerous papers that rely on the model (Cole et al. 2016a, 2016b; Mai et al. 2016a, 2016b, 2014; Lantz et al. 2014, Mignone et al. 2012).
} 
with decarbonization of the electric sector. However, in isolation, this approach may not be sufficient to achieve economy-wide GHG reductions of $83 \%$ below the 2005 level. As a result, additional GHG abatement options, such as increased use of biomass- or hydrogen-based fuels (for both energy and feedstocks), CCUS, and/or nuclear energy for industrial thermal processes may be required to achieve this deeper reduction goal. Finally, we demonstrate that moderate increases in end-use efficiency can substantially reduce the power system investment required to meet the growing electricity demand under the highly electrified future.

While this study focuses on the potential for and impacts of a high electrification pathway, we do not assess the risks or barriers to electrification or the cost associated with the infrastructure investments (e.g., vehicle charging stations) outside of the power sector that would be necessary to support electrification of end uses. Furthermore, we do not compare these scenarios to alternative GHG abatement pathways and, as a result, we do not judge or evaluate the likelihood of these pathways or their merit relative to other strategies. Achieving a low-carbon future at lowest cost will likely require a multi-faceted approach involving electrification and a suite of other abatement options that are not the focus of this study.

\section{Background}

In 2014 , combustion of fossil fuels accounted for the large majority—approximately $76 \%$ - of the total 6,870 million metric tons $(\mathrm{Mt})$ of carbon dioxide equivalent $\left(\mathrm{CO}_{2}-\mathrm{e}\right)$ emissions in the United States (EPA 2016a). ${ }^{3}$ Electrification of end-use technologies and simultaneous decarbonization of electricity generation is one approach to reducing these combustion-related GHG emissions. By substituting the use of fossil fuels, including coal, natural gas, and petroleum-based fuels, with (increasingly) lower carbon intensity generation sources, ${ }^{4}$ electrification and power system decarbonization can reduce emissions associated with fossil fuel combustion in end-use sectors. Given that the carbon intensity of electricity has been declining in recent years even in the absence of measures to lower the carbon intensity of the grid, electrification of some end uses can still yield emissions savings. ${ }^{5}$ In addition, any reductions in fossil fuel consumption associated with electrification could lead to reductions in domestic coal, oil, and natural gas production and transmission and result in reduced upstream emissions. ${ }^{6}$ Our analysis focuses on combustion-related emissions only, but we note that these upstream emissions can be significant - they comprise 7\% of 2014 U.S. GHG emissions (EPA 2016a).

Combustion-related GHG emissions, predominantly $\mathrm{CO}_{2}$ but also including $\mathrm{CH}_{4}$ and $\mathrm{N}_{2} \mathrm{O}$, are distributed across all sectors of the economy, with the power sector historically the largest source of GHG emissions in the United States (Figure 1). In 2014, the power sector comprised approximately $39 \%$ of the $5,216 \mathrm{Mt}$ of $\mathrm{CO}_{2}$-e combustion-related emissions nationally, followed

\footnotetext{
${ }^{3} \mathrm{GHG}$ emissions include $\mathrm{CO}_{2}$, methane $\left(\mathrm{CH}_{4}\right)$, nitrous oxide $\left(\mathrm{N}_{2} \mathrm{O}\right)$, and fluorine-containing substances (HFCs).

${ }^{4}$ Lower-intensity generation sources include nuclear, renewable, and fossil fuel with CCUS technologies.

${ }^{5}$ See, for instance, (Elgowainy et al. 2010; McLaren et al. 2016), comparing electric and conventional vehicle emissions under different grid intensities.

${ }^{6}$ However, the extent to which these upstream emissions are reduced will depend on fossil fuel exports to other countries. Conversely, reduced fossil fuel consumption could reduce upstream emissions from production outside the United States.
} 
by transportation (34\%), industry (15\%), and residential and commercial buildings (11\%) (EPA 2016a). Given the large share of emissions from the power sector, decarbonization of electricity generation alone could have a significant impact on economy-wide emissions. For example, reducing the emissions intensity of generation by $80 \%$, a level demonstrated to be achievable in a wide range of studies (Mai et al. 2014; MacDonald et al. 2016), would result in a reduction of almost 1,650 Mt of $\mathrm{CO}_{2}-24 \%$ of total U.S. GHG emissions (and almost one-third of combustion emissions). Coupling decarbonization of the grid with electrification of end-use processes has the potential to address an even larger share of combustion-related GHG emissions.

Direct Emissions Only

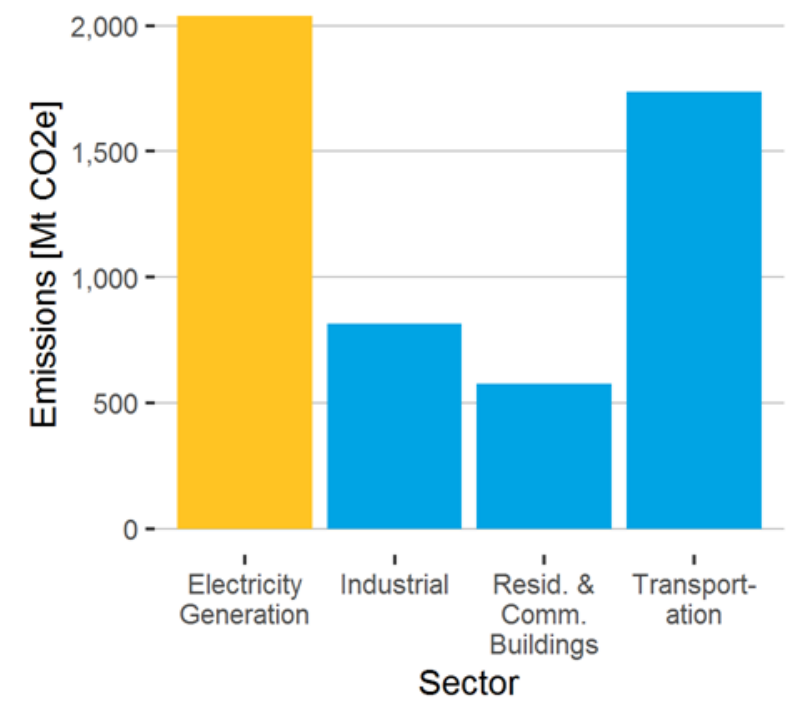

Electricity Related Direct Emissions
Direct \& Indirect

(Elec. Gen. Emis. Distributed)

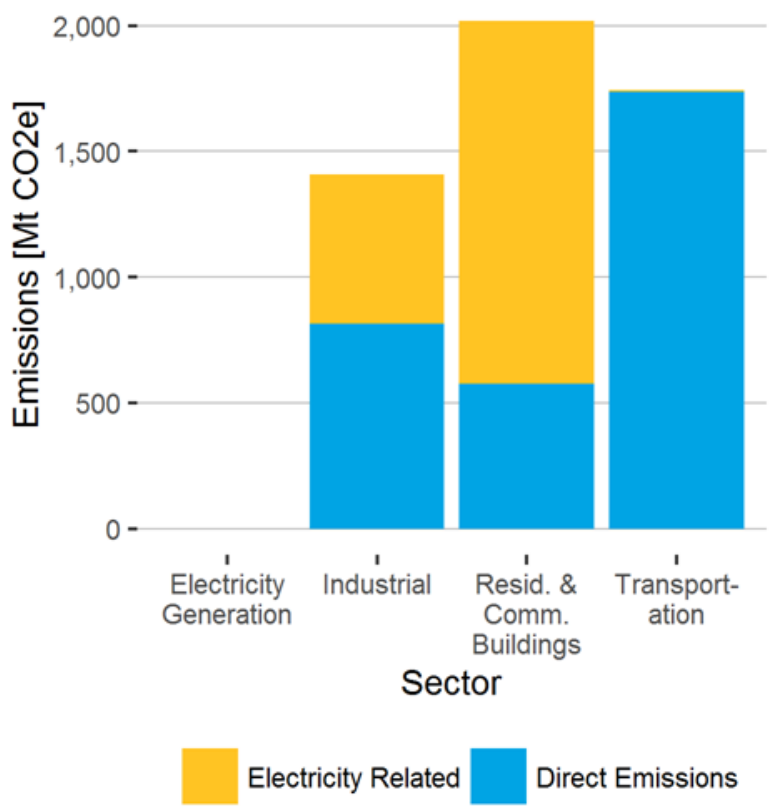

Source: Environmental Protection Agency (EPA) Greenhouse Gas Inventory (EPA 2016a)

Figure 1. 2014 GHG emissions from fossil fuel combustion by sector (left) and by sector with emissions associated with electricity generation distributed to end-use sectors (right)

Electrification has the potential to address the direct combustion emissions associated with enduse services in the transportation, industrial, ${ }^{7}$ and buildings sectors, which accounted for 3,158 $\mathrm{Mt} \mathrm{CO}_{2}$-e emissions, or 46\% of total U.S. GHG emissions in 2014 (EPA 2016a). The transportation sector made up the largest share of direct combustion emissions $\left(1,754 \mathrm{Mt} \mathrm{CO}_{2}\right.$-e) and, as a result, has a large potential for direct emissions reductions (EPA 2016a). Furthermore, Figure 1 demonstrates that emissions in the transportation sector are almost entirely due to direct fossil fuel combustion. Thus, given sufficient feasibility to substitute electric vehicles (EVs) for conventional vehicles and lowering carbon intensity of the grid, electrification in the transportation sector could represent a large potential for GHG reductions.

\footnotetext{
${ }^{7}$ Combustion emissions comprise just over $52 \%$ of total emissions in the industrial sector. Direct process emissions - for example, those from natural gas and petroleum systems and those emitted during iron and steel production-make up the remaining.
} 
As shown in Figure 2, on-road vehicles are responsible for the majority of transportation-related GHG emissions. In particular, emissions from light-duty vehicles (LDVs), which include passenger cars and light-duty trucks, totaled approximately $1,060 \mathrm{Mt} \mathrm{CO}_{2}(61 \%$ of total sector combustion emissions) while emissions from medium- and heavy-duty vehicles (M/HDVs ${ }^{8}$ ) totaled an additional $403 \mathrm{Mt} \mathrm{CO}_{2}$ (23\% of total sector combustion emissions). Combustion emissions from all other transport modes together made up the remaining $16 \%$ of total transportation sector combustion emissions (EPA 2016a; Davis et al. 2016).

In this analysis, we only explore the electrification of LDVs and M/HDVs. Electrification of these vehicle classes is assumed to be achieved by replacing conventionally fueled vehiclesthose that use petroleum-based fuels such as gasoline and diesel-with a range of alternative vehicles including plug-in hybrid electric vehicles (PHEVs), battery electric vehicles (BEVs), and fuel cell vehicles (FCVs). ${ }^{9}$ Other transportation modes, such as aviation, marine, and rail, are excluded from our electrification potential estimates. Nonetheless, combustion emissions from on-road vehicles account for over $84 \%$ of transportation sector combustion emissions (and $81 \%$ of total transportation sector emissions), ${ }^{10}$ so our analysis encompasses the majority of the potential for emissions reductions through electrification (EPA 2016a). As indicated earlier, the scope of our analysis focuses on electrification only and does not include scenarios with increased adoption of other lower-emitting fuels (e.g., biofuels).

\footnotetext{
${ }^{8}$ In this report, we group medium- and heavy-duty vehicles into the single category of "heavy duty."

${ }^{9}$ In this analysis, FCVs are considered an electrified technology if the hydrogen fuel is produced through electrolysis.

${ }^{10}$ Total transportation emissions, as defined here, include emissions from use of HFCs but excludes the $215.3 \mathrm{Mt}$ $\mathrm{CO}_{2}$-e emitted from non-transportation mobile sources in the agricultural and construction subsectors.
} 


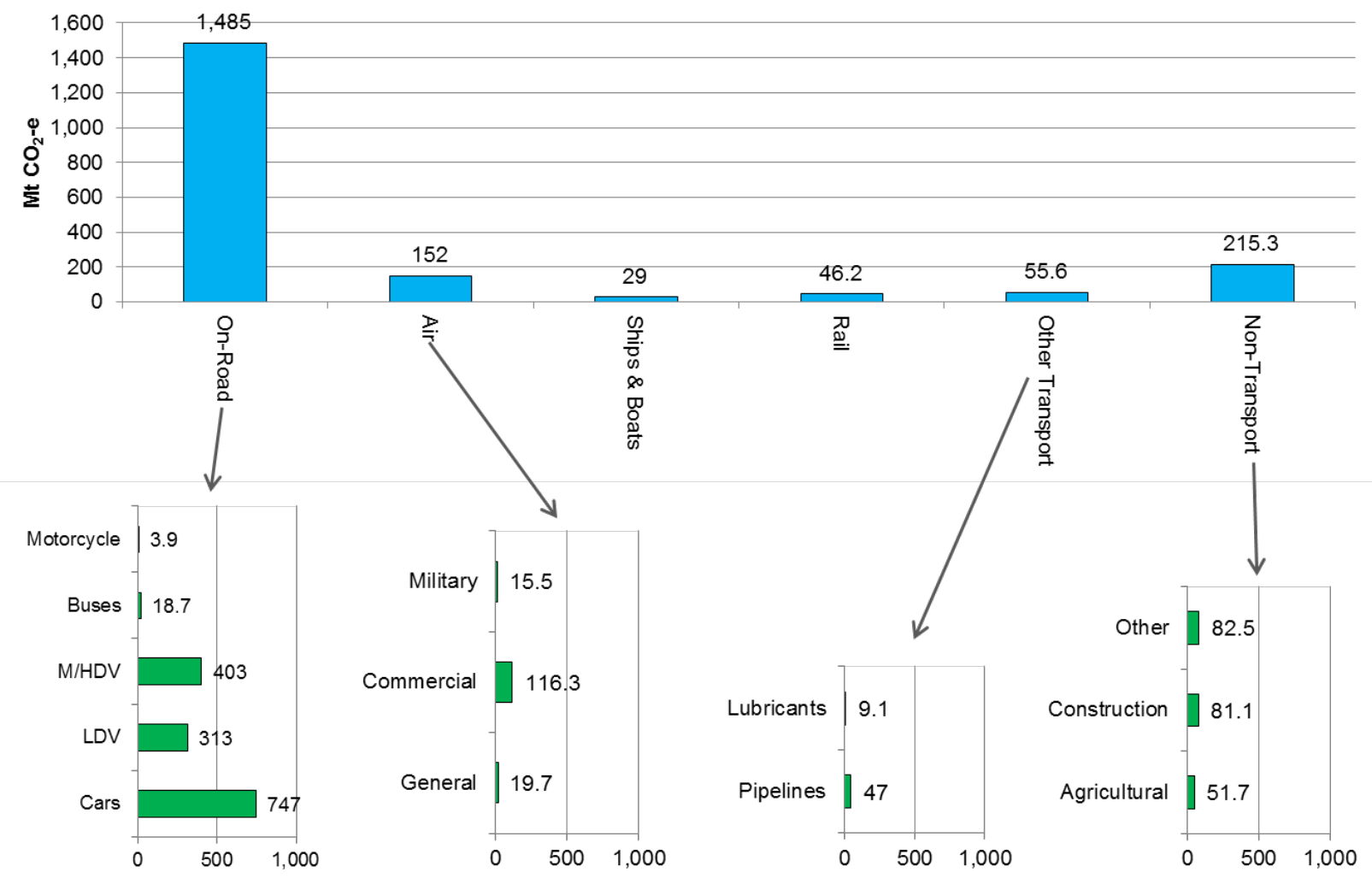

Source: EPA Greenhouse Gas Inventory (EPA 2016a)

Figure 2. 2014 GHG emissions from fossil fuel combustion in the transportation sector

The industrial sector accounted for the second-largest share of end-use combustion emissions: $767 \mathrm{Mt} \mathrm{CO}_{2}$-e in 2014 (EPA 2016a). ${ }^{11}$ These emissions are associated with a range of industrial end-use demands, including process heating, process cooling and refrigeration, machine drive, facility HVAC, facility lighting, hot water or steam production, onsite transportation, and combined heat and power. Industrial combustion emissions make up approximately $52 \%$ of total direct industrial emissions (1,461 $\mathrm{Mt} \mathrm{CO}_{2}$-e) and are largely accounted for by consumption in the combined heat and power, boiler, and process heat subsectors. The remaining $48 \%$ of total industrial emissions are largely from fossil fuel production and non-combustive industrial processes (e.g., production of petrochemicals, cement, iron and steel, lime, and nitric acid). Thus, electrification of industrial processes could, in theory, reduce approximately half of industrial emissions; ${ }^{12}$ however, given technology limitations, it is likely unrealistic to assume that all fossil fuel combustion processes could be electrified, particularly those that require extremely high temperatures, or those that require combinations of heating and the facilitation of oxidationreduction reactions (Ahman and Nilsson 2015). ${ }^{13}$

\footnotetext{
${ }^{11}$ This value excludes the $51.8 \mathrm{Mt} \mathrm{CO}_{2}$-e emitted through combustion of fossil fuels in the agriculture sector.

${ }^{12}$ As noted earlier, if economy-wide electrification greatly reduces the demand for and production of fossil fuels, additional non-combustive emissions savings such as reductions in $\mathrm{CH}_{4}$ leakage would likely be achieved in the industrial sector.

${ }^{13}$ Additional opportunities exist to reduce emissions from non-combustive processes, such as substitution of fossilfuel-based feedstocks with alternative bio- or hydrogen-based fuels.
} 


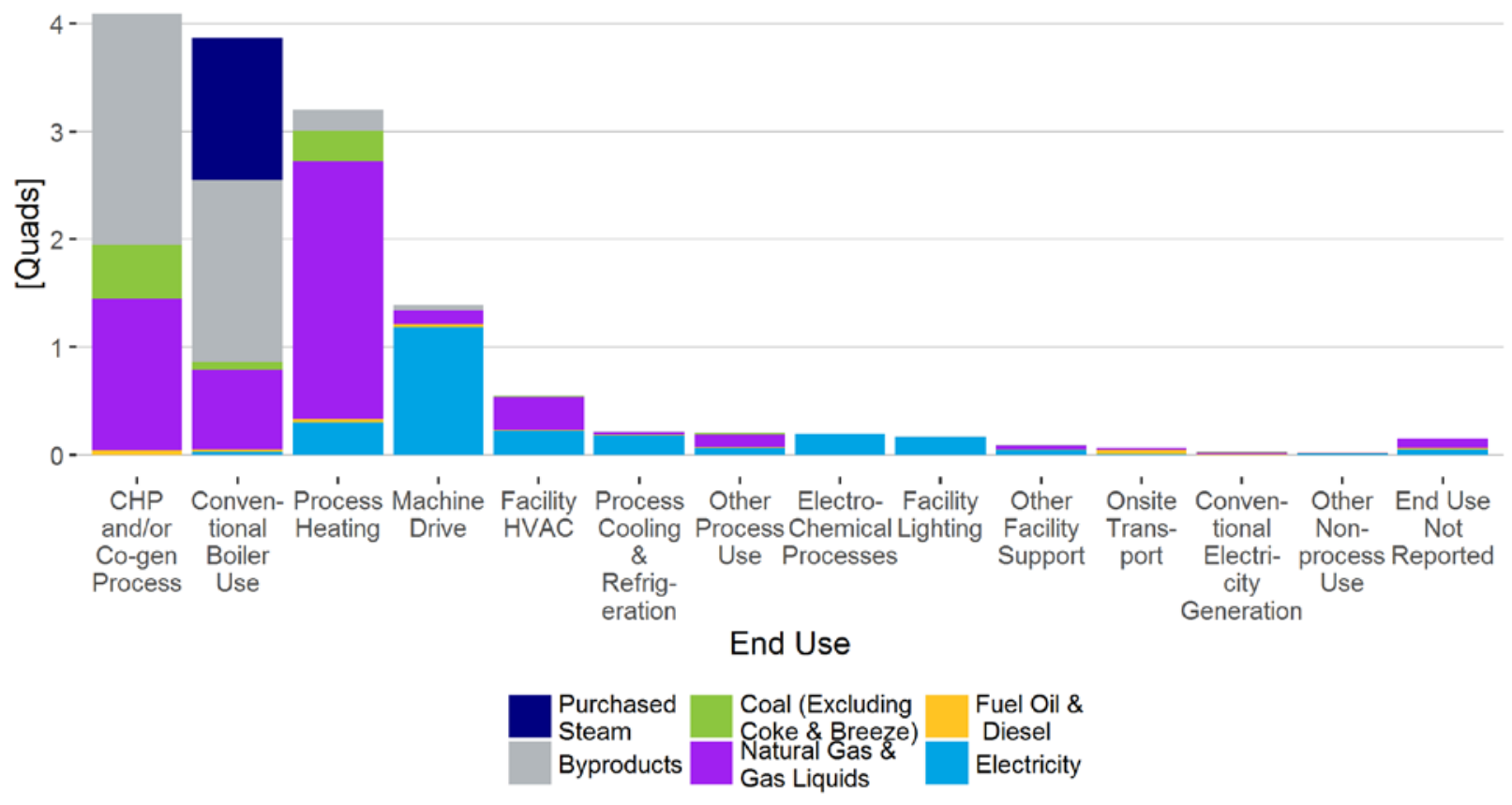

Source: Energy Information Administration's (EIA's) Manufacturing Energy Consumption Survey (2010)

Figure 3. Industrial energy consumption as a fuel by end-use service and energy type (2010); data exclude energy consumption as a non-fuel (feedstock)

Finally, the residential and commercial buildings sector, despite being the overall largest consumer of primary energy, ${ }^{14}$ accounts for the smallest portion of direct combustion emissions (577 $\mathrm{Mt} \mathrm{CO} 2$-e) (EPA 2016a). This is due in part to the fact that the buildings sector is already highly electrified - $48 \%$ of final energy demand is electric (EIA Annual Energy Review). ${ }^{15}$

Despite this already high level of electrification in the buildings sector, significant amounts of natural gas and, to a lesser degree, fuel oil and propane, are used for space conditioning, water heating, cooking, and other end-use services. Unlike the industrial and transportation sectors, with few exceptions (e.g., home emergency back-up generators), all fossil-fueled end-use service demands in buildings can currently be electrified. However, although viable electric end-use technologies exist for these service demands, some are either not yet cost-competitive or are not yet consumer-preferred options relative to traditional technologies. ${ }^{16}$

\footnotetext{
${ }^{14}$ Assumes primary energy used in electricity generation is distributed to end-use sectors based on the share of electricity sales.

${ }^{15}$ Final energy demand includes direct consumption of fuel, including natural gas, coal, petroleum fuels, biofuels, and electricity. Energy losses associated with the generation of electricity are excluded from final energy.

${ }^{16}$ For instance, despite electric stoves being cost-competitive and widely available, gas-fueled stoves are typically preferred over electric stoves. This could change, however, as electric alternatives, such as induction stoves, continue to decrease in cost and increase in popularity. Furthermore, air-source heat pumps for space conditioning, such as ductless mini-splits, continue to gain popularity, particularly in the retrofit market.
} 
Space heating, water heating, and cooking account for the large majority of fossil fuel use in residential and commercial buildings, as shown in Figures 4 and 5. ${ }^{17}$ In 2009, approximately 4.7 quadrillion BTUs (quads) of natural gas, 0.6 quads of fuel oil, and about 0.5 quads of propane were used in the residential sector, with almost all of that occurring in space and water heating (EIA 2009). Cooking (both indoor and outdoor), included in the "other" category, and "other uses," which include pool and hot-tub heaters, generators, and other small motors (e.g., lawn mowers), account for the remaining share of direct fossil fuel use. ${ }^{18}$ In the commercial buildings sector, a similar heavy reliance on natural gas and fuel oil is seen for space heating, water heating, cooking, and other uses (Figure 5). As a result, there exists a significant potential for electrification in the residential and commercial buildings sector, particularly in the space and water heating end uses, where adoption of electric technologies is already rapidly accelerating with the advent of "on-demand" water heaters and residential- and commercial-scale heat pumps such as "mini-splits."

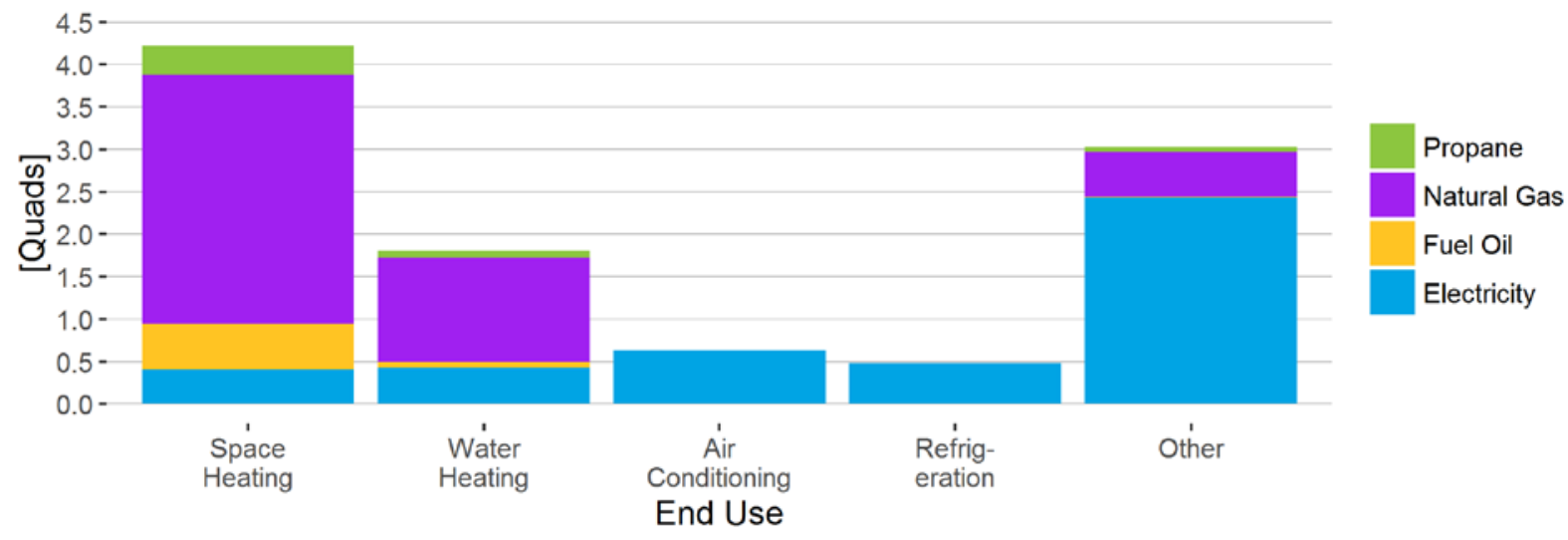

Source: EIA's Residential Energy Consumption Survey (RECS)

Figure 4. Final energy use in residential buildings by source and application-2009 residential energy consumption survey

\footnotetext{
${ }^{17}$ This figure shows final energy and not primary energy use. The difference is mainly applicable in the "electric" energy source, which excludes losses in the production and generation process when only final energy is reported. For most fossil fuels, these losses can amount to two-thirds of total primary energy use. Thus, the height of the lightblue columns could be up to two times higher than shown in the figure if represented as primary energy instead of final.

${ }^{18}$ In the residential buildings sector, "other uses" for electricity includes small electric devices, heating elements, and small motors not otherwise listed and for natural gas includes outdoor grills, exterior lights, pool and spa heaters, and backup electricity generators.
} 


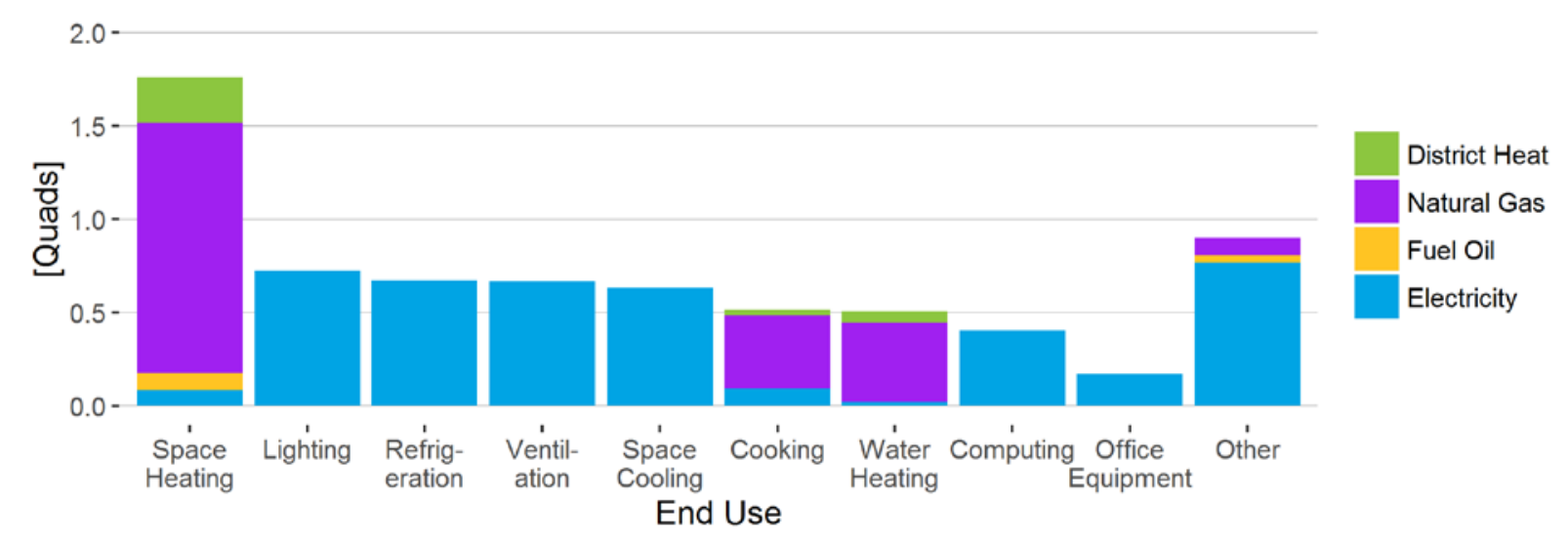

Source: EIA's Commercial Buildings Energy Consumption Survey (CBECS)

\section{Figure 5. Final energy use in commercial buildings by source and application-2012 commercial buildings energy consumption survey}

\section{Methods}

Our analysis addresses four main questions:

1. What is the potential for widespread electrification of end-use services in the U.S. transportation, buildings, and industrial sectors?

2. If the potential were achieved, how would demand for fossil fuels and electricity change (in terms of annual consumption and hourly load shapes)?

3. Given the increase in electricity consumption associated with electrification, how would the generation and transmission system evolve to meet new loads (with and without restrictions on GHG emissions), and how could energy efficiency improvements limit the need for new generation and transmission capacity?

4. What are the energy consumption and emissions implications across the different scenarios considered in this analysis?

Technically, the large majority of existing fossil-fueled combustion processes could be electrified across all end-use sectors, but there are significant challenges, both physical and economic, in doing so. Thus, this analysis explores a scenario in which electrification of end-use processes is aggressively pursued, but some end uses, particularly in the industrial sector, are not electrified due to the potentially strong economic barriers to doing so. As a result, we do not describe our high-electrification scenario as achieving the "technical potential" but instead as a scenario of "widespread electrification" in which electrification is aggressively pursued across all economic sectors. Thus, our electrification scenario achieves a level of electrification that falls short of the technical potential but is likely well above levels expected under an "economic potential."

Our general approach is described in the following sections; however, additional details on methods, data sources, and assumptions for each sectoral analysis are found in the Appendix. We begin by describing the development of electricity consumption projections under widespread electrification and subsequently describe the electricity modeling analysis. 


\section{Electrification Projections}

For each sector, we develop electricity and fuel consumption projections by fuel type, end-use service, and region (U.S. state level) from present day to 2050 under three scenarios (Table 1): (1) a Reference case, under which little to no electrification occurs; (2) a high-electrification (HighElec) case, under which electricity consumption increases as electrified technologies increase in penetration and reach their potential by 2050; and (3) a high-electrification and highefficiency or High-Combined (HighComb) case, which is identical to the high-electrification case but assumes significant reductions in the energy intensity of end-use services as a result of efficiency improvements. None of the scenarios reflect a forecast of likely outcomes, and we do not consider costs or other potential barriers to electrification, such as market failures and institutional or behavioral barriers, in the construction of these scenarios.

The Reference projection is adapted from a combination of the projections from the Energy Information Administration's (EIA's) 2016 Annual Energy Outlook (AEO 2016) and the U.S. Department of Energy's (DOE's) Office of Energy Policy and System Analysis (EPSA) Base Case, which was developed using the EPSA version of the National Energy Modeling System (NEMS) (DOE 2017). ${ }^{19}$ We then conduct an analysis of each end-use service demand to assess the potential of electrifying the currently fossil-fueled end use. Different methods and tools were used for each of the three end-use sectors - buildings, industry, and transport — as described below and in the Appendix. Based on this analysis, we subsequently develop the HighElec and HighComb scenarios, which achieve the potential for electrification by 2050 for each end use and calculate the associated consumption of electricity and fossil fuels by end use, sector, state, and year.

Table 1. Description of the Electrification Scenarios

\begin{tabular}{lll}
\hline Scenario & $\begin{array}{l}\text { Scenario } \\
\text { Name }\end{array}$ & Scenario Description \\
\hline Reference & Reference & $\begin{array}{l}\text { No incremental electrification beyond that represented in the EPSA- } \\
\text { NEMS Base Case }\end{array}$ \\
\hline High Electrification & HighElec & $\begin{array}{l}\text { Electricity consumption increases as end uses are electrified, and } \\
\text { the full estimated potential for electrification is achieved by 2050 }\end{array}$ \\
\hline $\begin{array}{l}\text { High Electrification } \\
\text { and High Efficiency }\end{array}$ & HighComb & $\begin{array}{l}\text { Equivalent to the HighElec case but efficiency improvements lower } \\
\text { the energy intensity of electric end-use devices, resulting in } \\
\text { decreased electricity consumption relative to the HighElec case }\end{array}$ \\
\hline
\end{tabular}

The efficiency of both conventional and electrified technologies have important implications for the changes in electricity and fuel consumption driven by electrification. As a result, we develop two projections of electricity consumption under our high electrification scenarios - one that

\footnotetext{
${ }^{19}$ The EPSA-NEMS model projects energy consumption by end-use service for all sectors from present day to 2040 within the nine census regions of the United States. For this analysis the projections were extended to 2050 using average annual growth rates in end-use service consumption between 2030 and 2040. Projections are disaggregated to the state level based on the state's share of census region energy consumption by end-use service. The EPSA Base Case was used for the buildings and industry sectors, whereas transport relied on a slightly different baseline from the VISION default scenarios, which also relied heavily on projections from NEMS developed for the EIA's Annual Energy Outlook (AEO) 2016.
} 
assumes business-as-usual changes in the efficiency of end-use devices (the HighElec scenario) and a second that assumes a higher level of efficiency improvement (the HighComb scenario).

In order to explore how the power sector could evolve to meet the increased demand for electricity under these scenarios, it is necessary to understand not only how electrification could affect annual consumption but also how that increase in consumption is spread across the hours of the year, or, in other words, how electrification impacts hourly load shapes. If electrification increases load predominantly during peak hours, the requirements on the grid will be different (and likely much more significant) than if electrification largely drives increased demand in offpeak hours. Thus, in order to assess the impact that electrification has on hourly load shapes, we disaggregate the state-level annual electricity consumption projections for each end use into annual 8,760 hourly load profiles. Methods used to determine the 8,760 load shapes by region (state) varied by sector. Details of these methods can be found in the Appendix.

We summarize key assumptions used in the development of the electrification scenarios and associated electricity demand projections in each sector in the three sections below.

\section{Transportation}

In this analysis, we restrict our exploration of electrification options to on-road vehicles. Other transportation demand, such as in aviation, marine, and rail, are excluded from our electrification potential estimates. For some modes, such as aviation and marine, alternative methods for decarbonizing, such as through use of biofuels, hydrogen, or other synthetic fuels (derived from net-neutral carbon sources) in combination with increased energy efficiency, may be more viable. Furthermore, on-road vehicles dominate transport-related GHG emissions and energy use and therefore offer the largest electrification opportunities. The exclusion of non-road electrification likely has a relatively minor impact on our overall electrification potential and GHG emission estimates but bears further exploration in future analyses.

Scenarios of adoption of alternative fuel vehicles, described below, were developed separately for LDVs and M/HDVs. The impacts of these adoption rates on vehicle stock and fuel demands were then modeled using a modified version the Argonne National Laboratory's (ANL's) VISION model. ${ }^{20}$ VISION is an accounting tool that allows for calculation and tracking of electricity load, fuel consumption, and emissions from LDVs and M/HDVs, given exogenously specified adoption rates and efficiency of vehicle types. ${ }^{21}$ For this study, a number of extensions to the default version of VISION were made, and the default electric and FCV adoption rates were modified to align with our scenarios. The default version of VISION does not include BEV or FCV options for M/HDVs. These options were added to the model. In addition, we modified the model further to distinguish between long-haul and short-haul freight in order to account for the greater feasibility of electrifying short-haul applications. The Appendix provides further detail on these model changes and associated data assumptions. Finally, while we rely on the

\footnotetext{
${ }^{20} \mathrm{See}$ http://www.anl.gov/energy-systems/project/vision-model. We modify the VISION model by adding EV options, primarily for HDVs. See the Appendix for details.

${ }^{21}$ VISION accounts for the vehicle stock and vintage-based usage. The modeled fleet evolution will depend on the market share and the age (and associated usage) of the vehicle fleet.
} 
default vehicle sales numbers from VISION for the Reference scenario, ${ }^{22}$ the electrification scenarios relied on our own specified adoption rates as outlined below.

Under the electrification scenarios, we assume that sales of conventional LDVs are phased out between present day and 2040, as consumers adopt greater shares of alternative fuel vehicles, including PHEVs, BEVs, and FCVs, such that by 2050, the LDV mix is dominated by alternative fuel vehicles (Figure 6). ${ }^{23}$ Light-duty PHEVs, BEVs, and FCVs are all available on the market today, but in order to achieve the high rate of adoption simulated under the HighElec case, we implicitly assume that challenges to adoption, such as the limited range of BEVs, are overcome through technological improvements. Hydrogen fuel for FCVs is assumed to be produced through electrolysis, and the associated electricity consumption for hydrogen production is included in our projections of electricity consumption. Although most hydrogen is currently produced through steam methane reforming, ${ }^{24}$ this approach allows us to bound the potential impact of hydrogen-production-associated electricity demands on the grid.

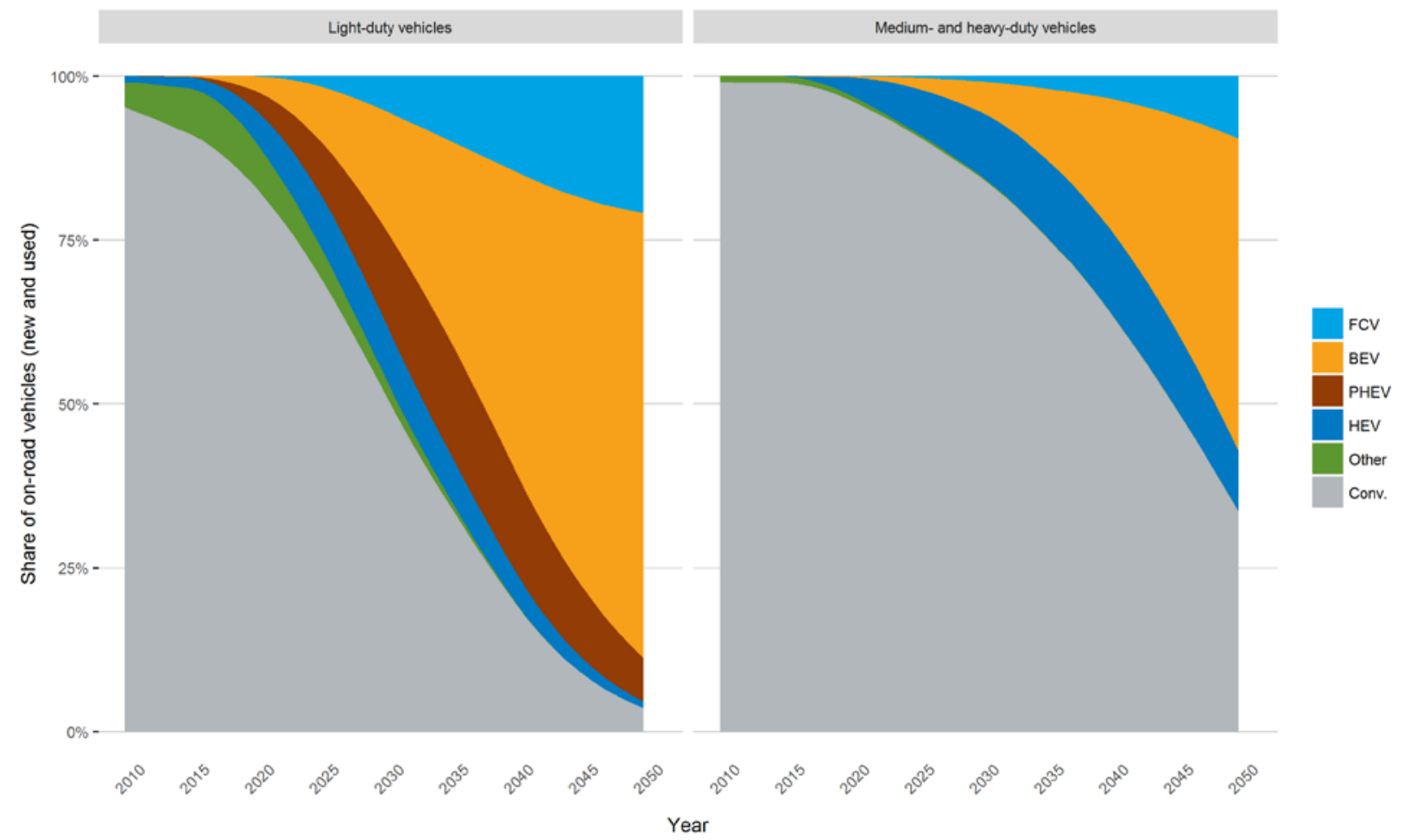

Figure 6. Total market penetrations of vehicle types from 2010 to 2050 for light-duty, and mediumand heavy-duty vehicles. ${ }^{25}$

\footnotetext{
${ }^{22}$ The default market share parameters from VISION are largely based on the AEO 2015 Reference case.

${ }^{23}$ Although they do not contribute to electrification by drawing electricity from the grid, we also assume increased penetration of HEVs relative to the baseline scenario.

${ }^{24}$ Today, roughly $95 \%$ of hydrogen produced in the United States is made through methane reforming.

${ }^{25}$ Heavy-duty vehicles here include all class 3-8 trucks. Medium- and heavy-duty trucks are classified by the rated maximum loaded weight of the truck, known as the gross vehicle weight rating (GVWR). The GVWRs of each class truck are as follows: 10,000-14,000 lbs (class 3); 14,001-16,000 lbs (class 4); 16,001-19,400 lbs (class 5); 19,50126,000 lbs (class 6); 26,001-33,000 lbs (class 7); and over 33,001 lbs (class 8).
} 
Similar to the LDV market, we assume increasing market penetrations of BEVs and FCVs in the $\mathrm{M} / \mathrm{HDV}$ market through 2050. However, we assume that BEVs and FCVs enter the market more gradually than they do for LDVs ( $16 \%$ of new sales in 2030 compared to $52 \%$ for LDVs), ${ }^{26}$ and we base our relative shares of sales for class 3-6 and class 7-8 BEVs and FCVs on projected proportions of vehicles within each category used for short-haul and long-haul applications. The proportions we use are based on data underlying EPA's MOVES model (EPA 2015). ${ }^{27} \mathrm{We}$ assume that BEVs are adopted for short-haul applications, while FCVs are adopted for long-haul applications. Class 3-6 trucks are predominantly used for short-haul purposes (short-haul makes up $97 \%$ of class 3-6 applications), and therefore, by $2050,97 \%$ of sales of class 3-6 vehicles are BEVs. Class 7-8 trucks are relatively evenly split between short- and long-haul applications, and thus $53 \%$ of sales of class $7-8$ trucks are BEVs and $47 \%$ are FCVs by 2050 .

For the HighComb scenario, we assume the same vehicle market penetration as in the HighElec scenario but assume greater efficiency increases over time for all vehicle types. In contrast to the Reference scenario in which the rate of improvement in fuel economies for all vehicle types slows over the 2025-2030 time period, we assume in the HighComb scenario that fuel economies for new vehicles diverge from the Reference scenario beginning in 2025 and continue to improve through 2050. In particular, vehicles purchased in 2050 have a $25 \%$ fuel economy improvement over the same vehicles from the Reference scenario. The improved fuel economy assumed in the HighComb scenario is loosely based on assumptions from the low-carbon scenarios in the Transportation Energy Futures (TEF) Study (Melaina et al. 2013; Stephens 2013; Plotkin et al. 2013).

The electrification scenarios are designed to assess very high levels of electrification and are not meant to consider all factors that might hinder or support vehicle electrification. Ultimately, the future degree of transport electrification will depend strongly on the interrelated impacts of future technology costs - particularly battery storage costs and utility rates - and consumer acceptance, infrastructure development, and policies. Among the technical considerations for future electrification, advancements in energy density will likely play a critical role as costs, vehicle weight, and vehicle range are all tied to it. For example, range anxiety has been noted as a key barrier to BEV adoption for passenger cars (National Research Council 2013; Stephens 2013). For trucks, the volume and weight of batteries not only reduces driving range, but can significantly reduce the hauling capacity. Electrified roadways could potentially be developed and deployed to address some of the barriers to on-road vehicle electrification, and are being tested in selected niches, such as campuses and dedicated freight corridors. These and other technical challenges pose barriers to electrification of non-road transport as well.

\section{Residential and Commercial Buildings}

As described above, the residential and commercial buildings sector is already highly electrified, but space heating, water heating, and cooking remain predominantly fossil-fueled services. Under the electrification scenario, space- and water-heating demands are assumed to be met increasingly with electric air- and ground-source heat pump technologies (and, to a lesser degree,

\footnotetext{
${ }^{26}$ The $52 \%$ for LDVs does not include PHEVs, which comprise $25 \%$ of sales in 2030.

${ }^{27}$ See the Appendix for details.
} 
electric resistance heaters), ${ }^{28}$ and induction stovetops are assumed to replace traditional gas or electric stoves. By 2050, the buildings sector is assumed to be $100 \%$ electrified.

Under the high-efficiency case, efficiency improvements in end-use devices are assumed to range from $0.2 \%-3 \%$ per year depending on the particular end-use device. For example, residential space heating technologies are assumed to improve efficiency by approximately $1 \%$ each year starting in 2017 relative to the reference scenario. Similarly, lighting efficiency improves by approximately 2\% annually between 2017 and 2050 as greater advances are assumed in solid state technologies. Energy efficiency improvement rates are estimated by the authors based on a range of projections from the literature, including DOE (2015e), Laitner et al. (2012), Wei et al. (2013), NAS (2010), and IEA (2011).

\section{Table 2. Annual Average Incremental Efficiency Improvement in Electric End-Use Devices from} 2017-2050 Assumed in the High-Efficiency Case

\begin{tabular}{|c|c|c|}
\hline End Use & Residential & Commercial \\
\hline Space Heating & $1.08 \%$ & $1.18 \%$ \\
\hline Space Cooling & $1.08 \%$ & $1.38 \%$ \\
\hline Water Heating & $0.73 \%$ & $0.57 \%$ \\
\hline Refrigeration & $0.73 \%$ & $0.79 \%$ \\
\hline Cooking & $0.52 \%$ & $0.56 \%$ \\
\hline Clothes Dryers & $0.52 \%$ & \\
\hline Freezers & $0.54 \%$ & \\
\hline Lighting & $1.95 \%$ & $1.86 \%$ \\
\hline ClothesWashers & $0.88 \%$ & \\
\hline Dishwashers & $0.78 \%$ & \\
\hline Televisions \& Related Equipment & $0.78 \%$ & \\
\hline Computers \& Related Equipment & $0.78 \%$ & \\
\hline Furnace Fans \& Boiler Circulation Pumps & $0.88 \%$ & \\
\hline Other Residential Uses & $0.79 \%$ & \\
\hline Ventilation & & $1.38 \%$ \\
\hline Office Equipment (PC) & & $0.55 \%$ \\
\hline Office Equipment (non-PC) & & $0.55 \%$ \\
\hline Other Commercial Uses & & $0.88 \%$ \\
\hline
\end{tabular}

\section{Industry}

End-use services in the industrial sector are generally recognized as more challenging to decarbonize than end-use services in the buildings and transportation sectors (Ahman and Nilsson 2015). In terms of decarbonization via electrification, this is due to both the large capital investments required to replace existing equipment, high relative cost of electricity as a fuel, and technical hurdles associated with electrifying certain energy-intensive and high-temperature processes (WSP Parsons Brinckerhoff 2015). Demand for process heat ${ }^{29}$ is the largest source of fossil fuel use and direct GHG emissions for the industrial sector (EIA 2013; EPA

\footnotetext{
${ }^{28}$ Significant improvements in air-source heat pumps have been achieved over the past decade, allowing them to be used at temperatures below $0^{\circ} \mathrm{F}$ while seeing tolerable declines in performance and capacity. However, in order to achieve $100 \%$ electrification of space heating, some resistance heaters will likely be required.

${ }^{29}$ Process heat can be separated into indirect heat (e.g., boilers) and direct heat (e.g., fuel burners and electric resistance heating).
} 
2016a). ${ }^{30}$ Additionally, industrial electric technologies that provide process heat were previously reported to have the greatest potential for national market growth (EPRI 2010). As a result, under this analysis, we limit our exploration of end uses in the industrial sector to conventional boiler use (i.e., boilers not used in combined heat and power applications) and the production of direct process heat.

Electric boilers and electric technologies for process heat production already exist and are in use in some industrial subsectors but currently make up only a small fraction of demand-fossil fuel combustion accounts for $99 \%$ of energy use in conventional boilers and $90 \%$ of direct process heat. ${ }^{31}$ Under our HighElec scenario, we assume that all conventional boilers are converted to electric technologies by 2050. Similarly, we assume that process heat production across the range of process heat end uses shown in Table 3 are $100 \%$ electrified by 2050, with the exception of direct arc melting for iron and steel production.

Table 3. Industrial End Uses and Electric Technologies Selected for Analysis

\begin{tabular}{|c|c|c|c|}
\hline Electrotechnology & Industry & End-Use Service & $\begin{array}{l}\% \text { Electrified by } \\
2050\end{array}$ \\
\hline Electrolytic reduction & $\begin{array}{l}\text { Nonferrous metals, } \\
\text { excluding aluminum }\end{array}$ & Process heating & $100 \%$ \\
\hline Induction heating & Metal fabrication & Process heating & $100 \%$ \\
\hline Electric boilers & $\begin{array}{l}\text { All manufacturing } \\
\text { industries }\end{array}$ & $\begin{array}{l}\text { Conventional boiler } \\
\text { use }\end{array}$ & $100 \%$ \\
\hline $\begin{array}{l}\text { Resistance heating and } \\
\text { melting }\end{array}$ & Glass & Process heating & $100 \%$ \\
\hline Direct arc melting & Iron and steel & Process heating & $21 \%$ \\
\hline $\begin{array}{l}\text { Industrial process heat } \\
\text { pump }\end{array}$ & $\begin{array}{l}\text { Food, pulp and paper, } \\
\text { chemicals }\end{array}$ & Process heating & $100 \%$ \\
\hline
\end{tabular}

The analysis was largely based on electrification opportunities technologies previously identified in a market potential analysis conducted by the Electric Power Research Institute (EPRI) (EPRI 2010). The cement industry, a significant source of energy use and GHG emissions, was excluded from the analysis based on a lack of electrification options identified in existing studies (CEMBUREAU 2013; WSP Parsons Brinckerhoff 2015). The iron and steel industry was assumed to undergo electrification via direct arc melting until 2020, at which point $21 \%$ of process heat demands are supplied with electric arc furnaces. No further electrification was assumed past 2020 due to the nascence of the arc furnace production route ${ }^{32}$ and the limits to available scrap that would be required for expanded arc furnace production.

\footnotetext{
${ }^{30}$ Process heat production accounts for $60 \%$ of total fossil fuel consumption in the manufacturing sector and over $40 \%$ of total industrial fossil fuel consumption, including agricultural, forestry, mining, and construction uses

${ }^{31}$ Data from the EIA (2010) adjusted according to the procedure described in Fox et al. (2011). The Thermal Spectrum of Low-Temperature Energy Use in the United States. Cornell University.

${ }^{32}$ Currently, the majority of steel produced from iron ore is produced by the blast furnace-basic oxygen furnace route (BF-BOF). The BF uses coke to reduce iron ore to liquid iron, which is then fed to the BOF where oxygen is introduced to oxide carbon and lower the carbon content of the molten metal. Direct reduced iron is produced by
} 
Under the high-efficiency scenarios, the energy efficiency of industrial processes (whether electricity or fossil-fueled) were assumed to improve by $0.8 \%$ per year relative to our Baseline scenario from 2017-2050. This estimate was developed by weighting the current opportunity for (state-of-the-art) energy reductions identified by DOE bandwidth studies (Choate 2003; Rue et al. 2007; DOE 2015a; DOE 2015b; DOE 2015c; DOE 2015d; DOE 2007a; DOE 2007b) by their relative fraction of 2010 manufacturing primary energy use (EIA 2013).

\section{Generation and Transmission Expansion Simulation}

Following the development of the electrification projections and associated hourly load profiles, we aggregate the changes in electricity loads across sectors and, using the ReEDS model, ${ }^{33}$ simulate the build-out and operation of the power system to meet these growing demands. The ReEDS model simulates the operation and expansion of the U.S. power system, including power plants, transmission, and storage from present day through 2050, in order to meet electricity demand and least cost from present day through 2050 (Eurek et al. 2016). The model chooses the cost-optimal mix of technologies that meet all regional electric power demand requirements, based on grid reliability (reserve) requirements, technology resource constraints, and policy constraints. ReEDS is designed with a high degree of spatial and temporal resolution and uses statistical approaches to address many of the unique characteristics of many renewable energy resources, such as location dependence and output variability and uncertainty. ReEDS captures temporal variability in load by aggregating 8,760 loads into 17 "time slices." These time slices capture the load patterns within a representative day in each season, and each representative day is further divided into four diurnal time slices ( 4 seasons and 4 times of day yields 16 time slices). In addition, there is one additional summer-peak time slice to capture the highest-demand hours in the year. These 17 annual time slices enable ReEDS to capture the intricacies of meeting electric loads that vary throughout the day and year-with both conventional and renewable generators.

The modeling scenarios we consider in ReEDS are summarized in Table 4. Essentially, our scenarios differ along two dimensions: (1) electrification and efficiency improvements and (2) carbon policy. The former consist of the Reference, HighElec, and HighComb scenarios described in the prior section. In order to understand the implications of electrification both with and without simultaneous power sector decarbonization, we consider two power sector carbon options. In our baseline scenarios, the carbon policies are the Clean Power Plan (CPP) and other existing sectoral policies; we assume compliance with the CPP is achieved through a mass-based cap-and-trade policy with the New Source Complement, and we allow for national carbon allowance trading. ${ }^{34}$ Power sector emissions beyond 2030 match their 2030 levels. In our decarbonization scenarios, we implement a hypothetical national $\mathrm{CO}_{2}$ cap-and-trade program

\footnotetext{
reducing iron ore below the melting point of iron, typically with natural gas, and can be used in an electric arc furnace to produce steel.

${ }^{33}$ This analysis used the ReEDS 2016 final release version of the model.

34 The implementation of the CPP has been stayed by the Supreme Court pending judicial review.
} 
that begins at the CPP level in 2022 (1,859 MMt) and decreases linearly until it reaches $409 \mathrm{Mt}$ in $2050,83 \%$ below the 2005 power sector emissions level. ${ }^{35}$

Table 4. Scenarios Simulated in the ReEDS Model

\begin{tabular}{lll}
\hline ReEDS Scenario & Electrification Scenario & $\begin{array}{l}\text { Power Sector } \\
\text { Carbon Policy }\end{array}$ \\
\hline Baseline & Reference & CPP only \\
$\begin{array}{l}\text { Baseline- } \\
\text { HighElec }\end{array}$ & High Electrification & CPP only \\
$\begin{array}{l}\text { Baseline- } \\
\text { HighComb }\end{array}$ & High Combined & CPP only \\
\hline Decarb & Reference & $83 \%$ Cap \\
Decarb-HighElec & High Electrification & $83 \%$ Cap \\
$\begin{array}{l}\text { Decarb- } \\
\text { HighComb }\end{array}$ & High Combined & $83 \%$ Cap \\
\hline
\end{tabular}

Natural gas and coal fuel price inputs for these scenarios are derived from the Annual Energy Outlook (AEO) 2016 Reference Case (U.S. Energy Information Administration 2016) through 2040. Beyond 2040, prices are held constant at the 2040 levels. ${ }^{36}$ Projected cost and performance characteristics of new generation infrastructure, including fossil, ${ }^{37}$ nuclear, and renewable generation technologies are from NREL's 2016 Annual Technology Baseline report Mid case (NREL 2016; Cole et al. 2016).

\section{Results and Discussion Electricity Demand Impacts}

In this section, we show the incremental load resulting from electrification aggregated across the buildings, industry, and transportation sectors. We also show how the aggregate incremental load is distributed across seasons and time of day. In the next section, we show the power sector evolution in order to meet this incremental load.

\footnotetext{
${ }^{35}$ The carbon cap implemented in the decarbonization scenario is not based on any existing or proposed federal policy. It has been shown that in the United States, the least-cost pathway to achieving an $83 \%$ reduction in economy-wide emissions (below 2005 levels) would likely require greater than $83 \%$ reductions in the power sector. Nevertheless, we explore the $83 \%$ target for the power sector as a nominally aggressive power sector emissions reduction target.

${ }^{36}$ ReEDS is a power-sector-only model but includes a representation of price elasticity of natural gas supply. Because our analysis represents an economy-wide transformation well beyond what is reflected in the elasticity assumptions, we suppress the elasticity in our scenarios and assume power-sector-delivered natural gas prices directly from the AEO.

${ }^{37}$ Fossil fuel technologies represented include those coupled with CCUS. The ReEDS model allows construction of both new coal and natural gas units with CCS and also allows natural gas units to be retrofit with CCS.
} 
Under our reference case, total U.S. electricity consumption grows from approximately 3,860 TWh in 2016 to 5,260 TWh in 2050. Consistent with results from other analyses of electrification impacts on electricity demand (Clarke et al. 2014; Williams et al. 2014), electrification of all end uses explored leads to over a two-fold increase in electricity consumption by 2050 (Figure 7). The transportation sector accounts for the majority of the incremental load $(50 \%),{ }^{38}$ with buildings $(27 \%)$ and industry $(23 \%)$ making up approximately equal shares of the remaining half.

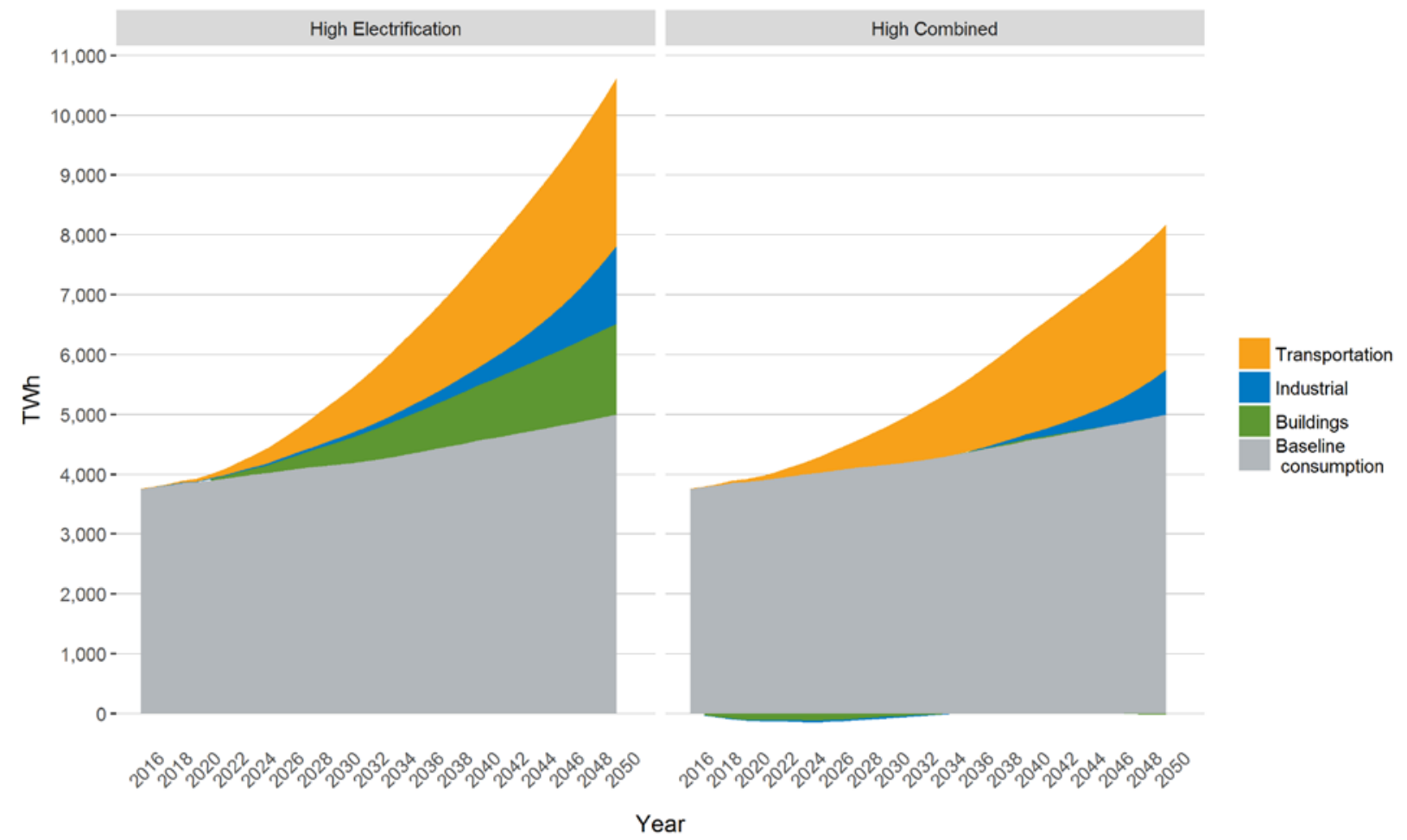

Figure 7. Reference and incremental electricity consumption from electrification by sector, 2016-2050

Energy efficiency improvements in electric technologies have the potential to substantially reduce the additional electricity load resulting from widespread electrification (Figure 7, right panel). Under the HighComb case, increases in electricity demand are driven exclusively by the industry and transportation sectors, as the efficiency improvements in the buildings sector (which ranged from $0.5 \%$ to $2 \%$ improvements per year, depending on the technology $y^{39}$ ) completely offset the buildings electricity load growth associated with electrification. As a result, the change in total building electricity consumption from the base case is negligible; however, load shapes are still impacted.

\footnotetext{
${ }^{38}$ In 2050, about half of the transport-related electricity consumption is from FCVs despite the fact that FCVs make up a smaller share compared to EVs. This is due to the assumed efficiency of electrolysis and our assumption that hydrogen is produced solely through electrolysis. Other assumptions would yield lower transport-related electricity consumption but would also have different emissions implications.

${ }^{39}$ By comparison, between 1987 and 2010, the average energy consumption of refrigerators decreased by over $50 \%$ and clothes washers by over $75 \%$. This represents an average annual increase in the efficiency of refrigerators and clothes washers of over $4 \%$ and $13 \%$ per year, respectively (Mauer et al. 2013).
} 
In addition to growth in total consumption, electrification also impacts the variability and shape of load. This is due to the fact that demands for the full range of electrified end uses - from space heating and cooling to personal transportation and industrial process heat production-occur at different times of the day and year. To demonstrate the aggregate impacts of electrification on load, we calculate the ratio of peak demand to average demand, which is illustrated in Figure $8 .{ }^{40}$ Under our reference case, by assumption, the peak-to-average demand remains constant through time (i.e., load shapes do not change through time). Implicitly, this means that under our Reference case, we assume limited effects of increased demand-side management, changes in rate structures, growth in electrification, or other changes in demand-side drivers. Under the HighElec scenario, as we incorporate incremental load due to electrification, the peak-to-average ratio decreases substantially through time. This demonstrates that the rate of increase in peak demand as a result of electrification is slower than the rate of increase in average (or total) demand. This is predominantly driven by our assumption that EV charging and hydrogen production loads are highly flexible. Specifically, we assume that transportation electricity load does not occur during the top 40 peak load hours of the year.

Approximately half of the incremental transportation load is associated with the production of hydrogen. Given that hydrogen is relatively easily stored, shifting production to non-peak hours does not present substantial challenge. Thus, we assume that daily hydrogen demands are perfectly flexible within a 24-hour period. However, limiting direct charging loads for EVs to non-peak hours would likely require infrastructure investments (such as localized storage at charging facilities) and/or changes to rate structures to both provide an incentive for off-peak charging and to enable the load shifting. As a result, we assume that charging loads do not occur during the top 40 load hours of the year; however, vehicle charging still occurs during other high-load hours, including, for example, summer afternoons.

The resulting decrease in the peak-to-average demand ratio, as assumed for our electrification scenarios, has important implications for the evolution of the power sector: under our scenarios, electrification will drive the need for energy resources over capacity resources (i.e., resources that provide low-cost energy but may have higher capital costs, as opposed to resources that can provide low-cost capacity and are only expected to provide energy for short periods of time at high cost). Conversely, absent requisite infrastructure investments and electricity rate incentives, electrification - particularly transport electrification - could extend the peak-to-average demand ratio and correspondingly raise electricity costs and infrastructure needs.

\footnotetext{
${ }^{40}$ In Figure 8, "peak" demand is defined as the top 40 load hours during the summer afternoon, as modeled in the peak time slice in ReEDS. Increasing variable renewable generation can result in changes to net peak demands and therefore alter when the times of greatest electric system risk might occur. As such, Figure 8 only partially captures how electrification and the associated consumption pattern changes might impact electric system planning and reliability. Note that ReEDS captures these dynamics within its investment decision making.
} 


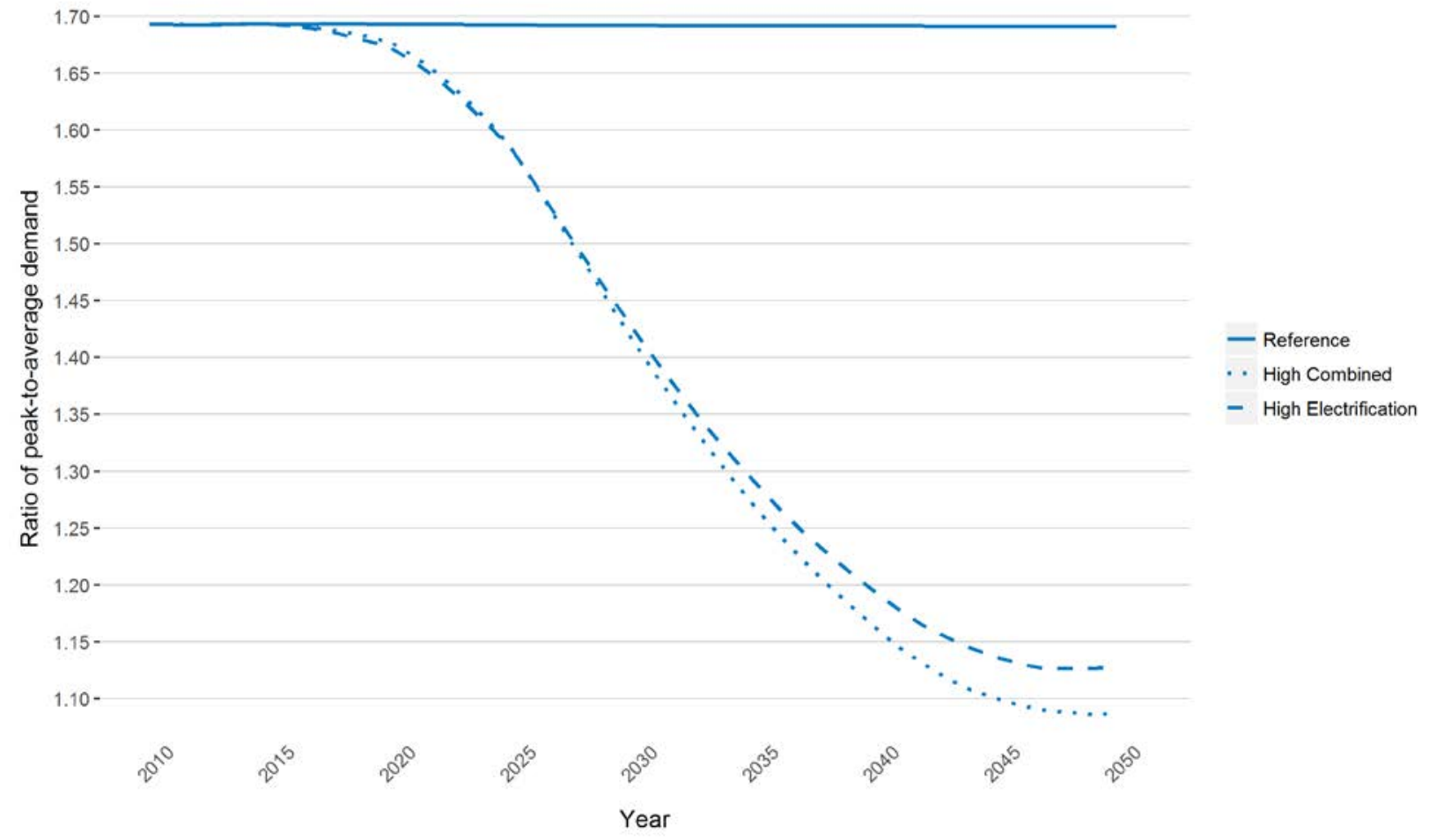

Figure 8. Peak-to-average demand ratio for the Reference, HighElec, and HighComb scenarios

\section{Power System Evolution}

\section{Generation and Capacity}

The HighElec and HighComb scenarios (regardless of carbon policy) both represent considerable growth in electricity consumption. As a result, substantial power sector investment is required to meet growing electricity demand. We first analyze the build-out of the power sector to meet the demands of electrification. We then analyze how decarbonization of the power sector could change this build-out.

The left panel of Figure 9 illustrates changes in the mix of electricity generation (top) and installed capacity (bottom) over time in the Baseline scenario. Under the Baseline scenario, we see two main trends - growth in renewable (wind and solar) and natural gas combined cycle (NGCC) capacity and retirement of existing coal capacity. These trends are driven jointly by moderate growth in load, relatively low natural gas prices, emissions reductions required by the CPP, near-term support for new renewable capacity through the production and investment tax credits, and reductions in renewable technology costs over time. 

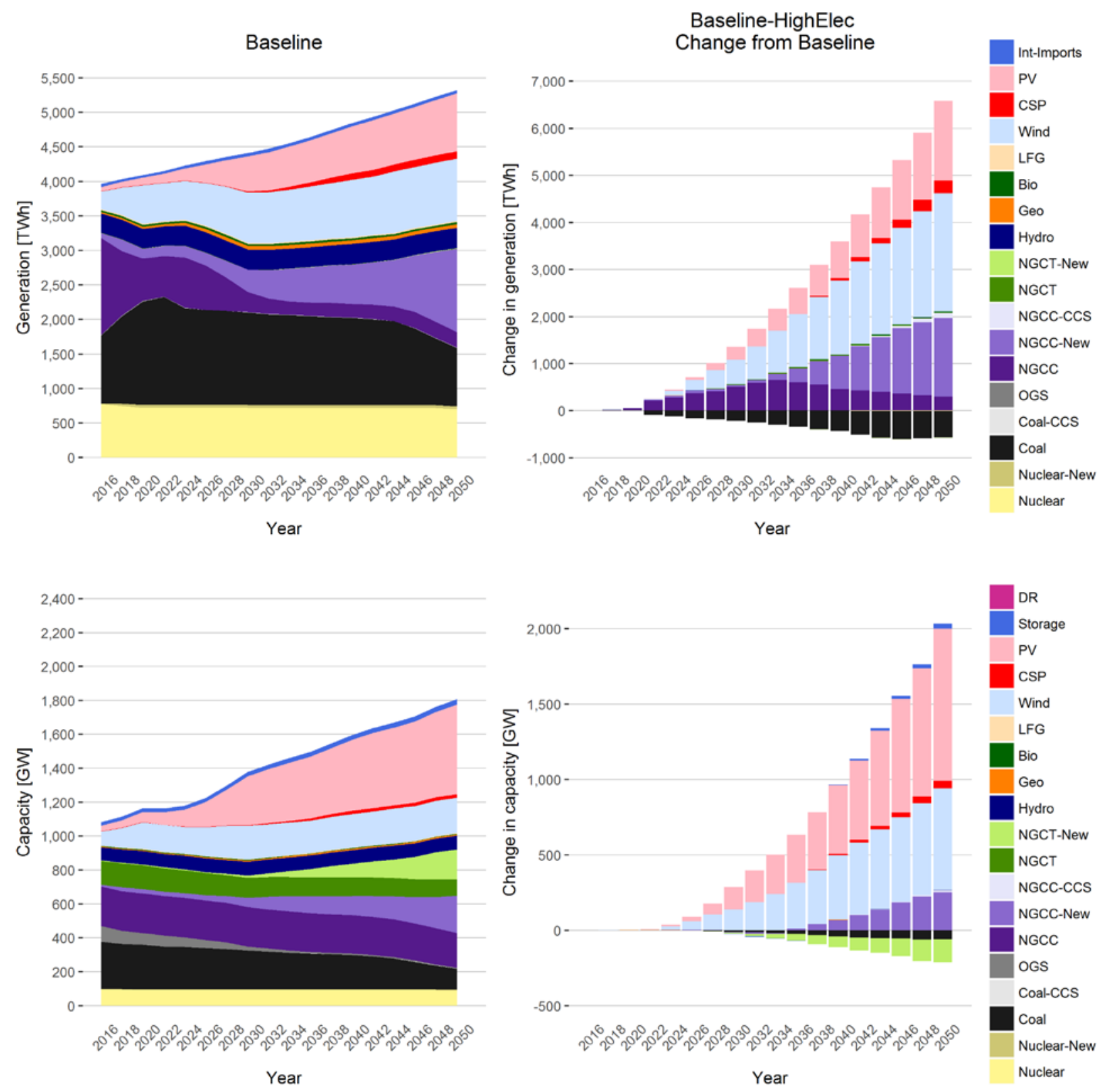

Figure 9. Generation (top) and capacity (bottom) mix over time for the Baseline scenario (left) and the difference between the Baseline-HighElec scenario and the Baseline scenario (right)

In the figure legends, abbreviations are used for the following technologies: international imports (IntImports), photovoltaics (PV), concentrated solar power (CSP), landfill gas (LFG), biomass (Bio), geothermal (Geo), hydroelectric (Hydro), natural gas combustion turbine (NGCT), natural gas combined cycle (NGCC), carbon capture and sequestration (CCS), and oil/gas steam (OGS).

The right panel of Figure 9 shows the change in generation and capacity mixes as a result of the increased electricity demand in the Baseline-HighElec scenario (compared to the Baseline scenario). Electrification of end uses creates a large need for new generation and capacity. To serve increased energy demand, generation nearly doubles by 2050 relative to the Baseline case. This additional generation is provided predominantly with new wind and solar capacity, increased generation from new NGCC plants, and, to a lesser extent, increased utilization of 
existing NGCC capacity. Under the Baseline-HighElec scenario, average annual additions of renewable generation capacity from 2020-2050 are approximately $65 \mathrm{GW}$ per year. Despite the fact that no additional nuclear generation is observed in the electrification, nuclear generation plays a role in meeting electrification needs as we assume that the leases for all existing nuclear plants (with exception of those that are already retired or planned to retire before 2020) are extended to 80 years. As a result, in both the Baseline case and the Baseline-HighElec scenarios, nuclear generation makes a substantial contribution to the generation requirements.

One of the key driving forces behind the mix of generation used to meet the additional electrification load is the CPP. We assume that compliance with the CPP is achieved through a mass-based approach with the New Source Complement targets and that the targets remain constant at their 2030 levels for all years following. As a result, $\mathrm{CO}_{2}$ emissions from the power sector are capped at the 2030 target level for all years following. Given that the CPP is binding in almost all years in the Reference case, this means that any new generation used to serve the electrification load must, by definition, have a net-zero impact on power sector emissionsadditional electricity must be generated, but emissions must stay fixed. As a result, all new generation must be either zero-carbon emitting, in the form of generation from renewable and nuclear technologies, or must substitute higher-emitting sources for lower-emitting sources (e.g., substituting coal generation with NGCC generation or substituting coal or gas generation with NGCC with CCUS generation). In fact, Figure 9 shows how, in the Baseline-HighElec scenario, existing coal plants are ramped down even further beyond the Baseline scenario and, as a result, additional coal capacity is retired. This reduction is a direct result of the emissions budget set forth by the mass-based CPP as the reduced coal generation can make way for about twice the NGCC generation under this high demand growth situation. ${ }^{41}$ If instead we assumed rate-based compliance with the CPP, we would likely see substantially higher emissions, as new generation would be allowed to emit at the final level of the rate-based targets.

Figure 10 illustrates the evolution of the power sector when electrification of end uses is accompanied by significant decarbonization of the power sector, specifically when we impose a cap requiring an $83 \%$ reduction in emissions below the 2005 level (in the power sector) by $2050 .{ }^{42}$ The left panel represents results for the Baseline-HighElec scenario while the right panel represents the differences that occur under the Decarb-HighElec scenario. Relative to the Baseline-HighElec scenario, when the power system is significantly decarbonized, in order to achieve greater emissions reductions, an increasing amount of coal and NGCC capacity and generation is displaced over time. Some of this displacement comes from variable renewable resources (solar PV and wind), but the majority comes from NGCC-CCUS. Moreover, concentrating solar power (CSP) deployment and usage is significantly higher, as is storage capacity. The additional use of NGCC-CCUS, CSP, and storage reflects the need for additional system flexibility in a high variable renewable resource regime.

\footnotetext{
${ }^{41}$ For all years following 2030, we assumed the CPP mass-based targets, including the new source complement, were held constant at the 2030 level.

${ }^{42}$ Note that this emissions cap is not based on any existing policy or proposal but is in line with the national emissions reduction target identified in the White House Mid-Century Strategy (EOP/CEQ 2016).
} 
These results highlight two key observations: (1) renewable generation is anticipated to grow significantly in all scenarios, but growth is particularly substantial under high electrification, and (2) despite the comparatively small role that CCUS capacity plays in our Baseline and BaselineHighElec scenarios, when deep decarbonization of the power sector is required, CCUS, and in particular NGCC-CCUS, has a significant role to play, particularly under scenarios in which electricity demand is growing at a high rate.

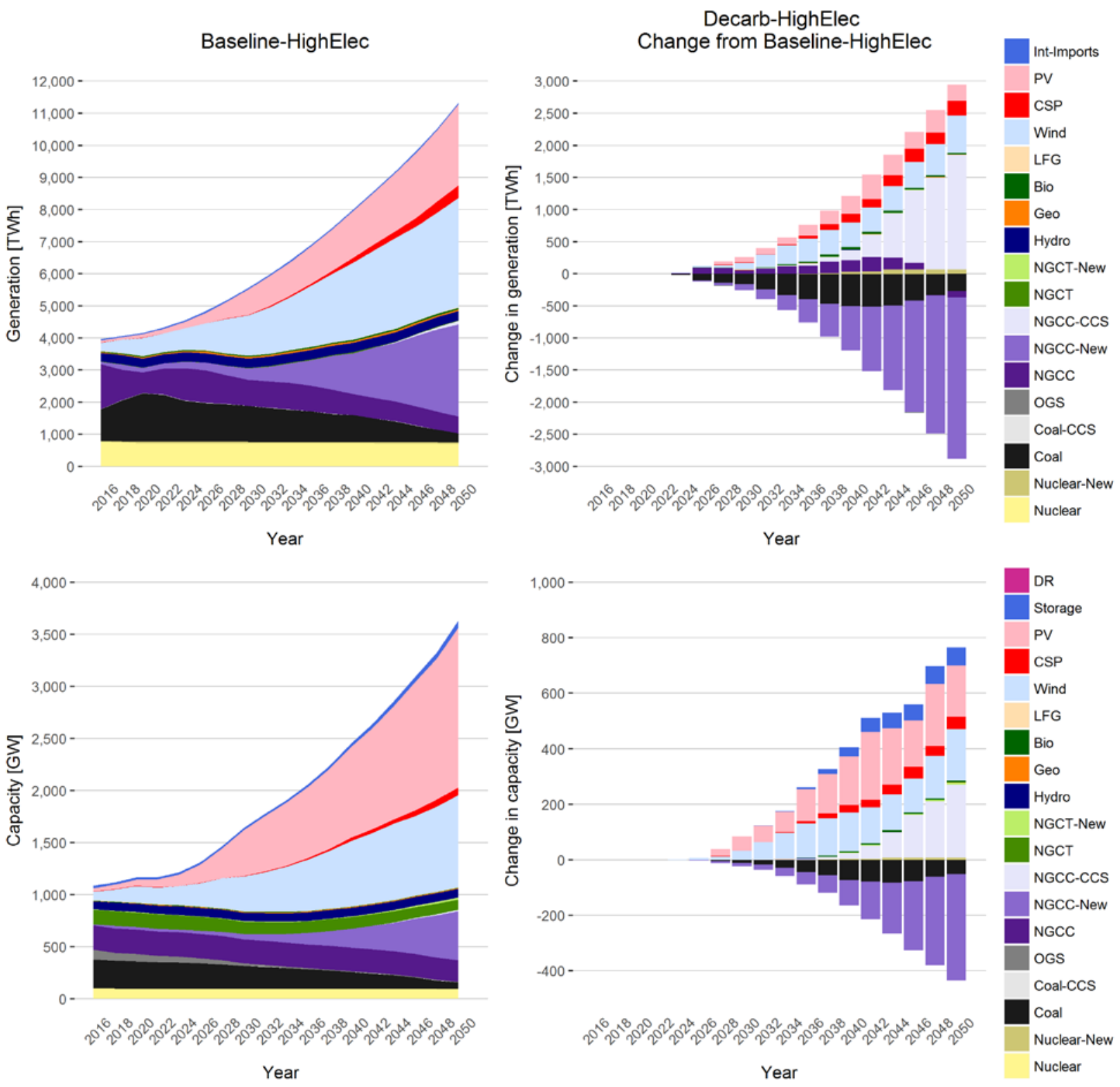

Figure 10. Generation (top) and capacity (bottom) mix over time for the Baseline-HighElec scenario (left) and the difference between the Decarb-HighElec scenario and the BaselineHighElec scenario (right)

Our discussion thus far has focused on the evolution of the power sector under highelectrification scenarios, which by design do not consider improvements in end-use efficiency beyond the improvements embedded within the Baseline case. We capture those improvements 
in our Baseline-HighComb and Decarb-HighComb scenarios. Figure 11 shows the impact of electrification combined with efficiency improvements relative to the Baseline case.
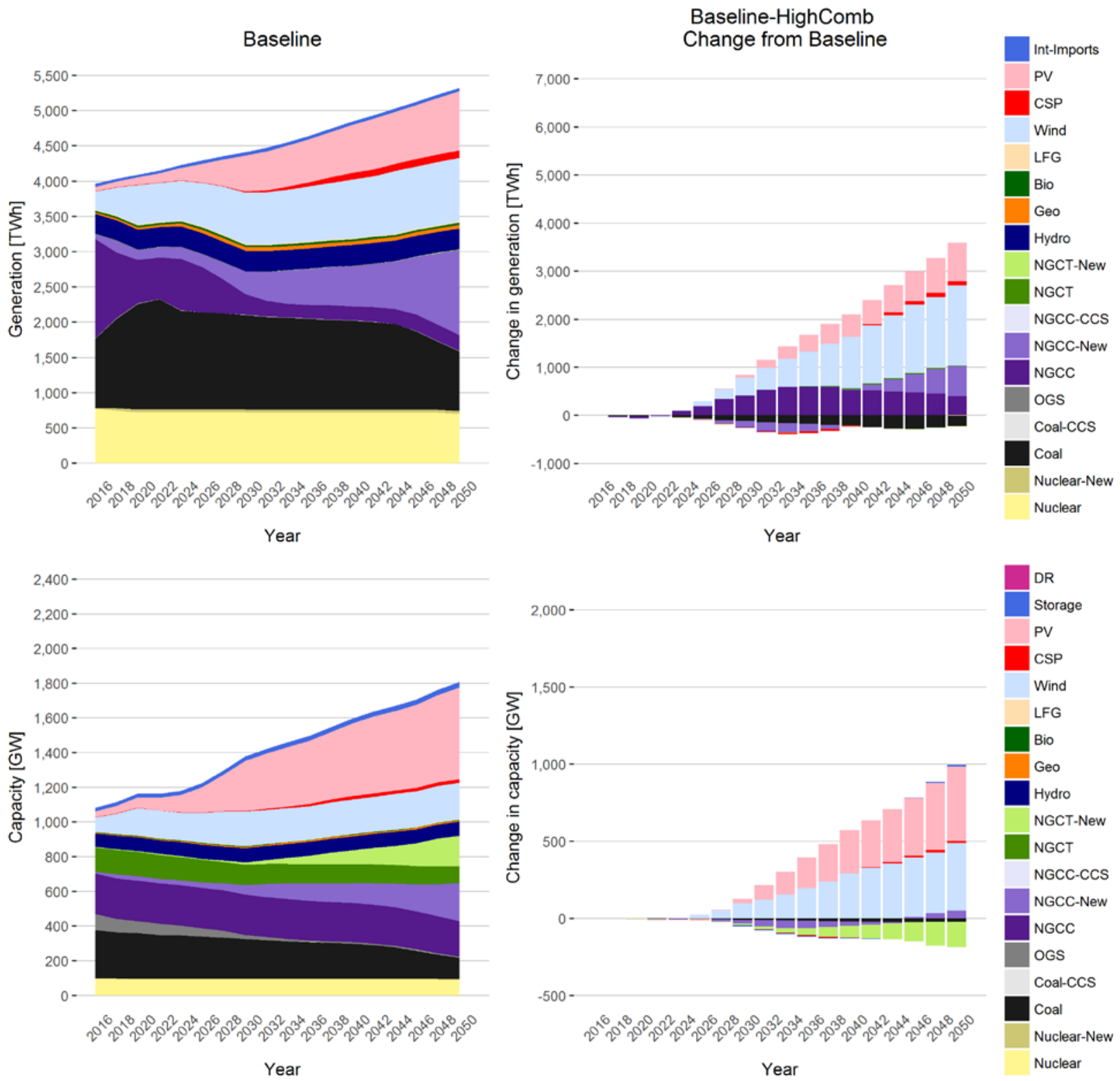

Figure 11. Generation (top) and capacity (bottom) mix over time for the Baseline scenario (left) and the difference between the Baseline-HighComb scenario and the Baseline scenario (right)

The compositional changes induced by combining both electrification and efficiency are similar (yet smaller) to the impacts of electrification alone. The additional load from electrification is largely met through increased renewable generation and increased generation from existing and new NGCC units. However, given that the incremental 2050 electricity consumption in the HighComb scenario is roughly half that of the HighElec scenario, the total additional required capacity and generation is significantly reduced relative to the HighElec scenario. Annual average additions of total renewable capacity fall from $65 \mathrm{GW}$ per year under electrification alone to approximately $40 \mathrm{GW}$ per year when additional efficiency improvements are made. 


\section{Variable Generation Curtailment}

The generation and capacity mix discussion makes it clear that all of our scenarios include significant increases in variable renewable penetration; this is particularly true for our highelectrification and decarbonization scenarios. Because of the non-dispatchable nature of these resources, high penetration levels can result in greater levels of curtailment, all else equal. However, our high-electrification scenarios also involve changes in both demand shape and level, so the end result is a priori ambiguous. In this section, we present the curtailment results from ReEDS.

Figure 12 illustrates the relationship between variable renewable penetration levels and average curtailments from those resources for the Baseline, Baseline-HighElec, Baseline-HighComb, Decarb, Decarb-HighElec, and Decarb-HighComb scenarios. Variable renewable penetration levels are defined as the percentage of total generation that comes from PV and wind. Average curtailments are calculated as the curtailed proportion of the total amount of electricity that variable renewable resources could provide (i.e., curtailments plus generation), expressed in percentage terms. ${ }^{43}$

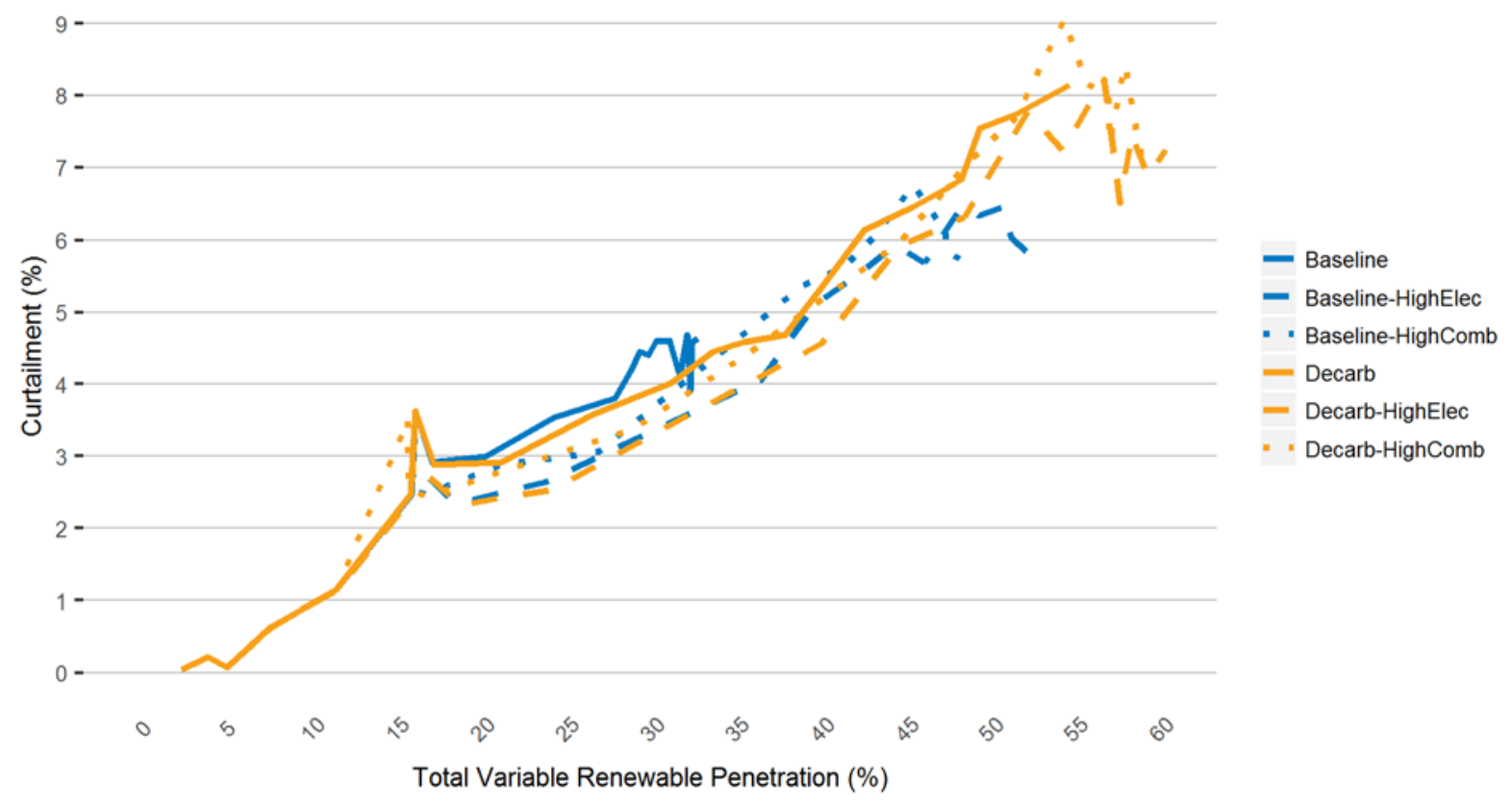

Figure 12. Relationship between variable renewable resource penetration and average curtailment

The basic trend for all scenarios is that higher penetration levels are associated with greater average curtailment and that curtailment tends to increase linearly with variable renewable penetration. However, for the same penetration levels, the high electrification scenarios appear to

\footnotetext{
${ }^{43}$ We present average curtailment percentages, but marginal curtailment (i.e., curtailment of capacity installed in the current model year) percentages tend to be much higher. For example, in the Decarb-HighElec scenario, national average marginal curtailment exceeds $25 \%$ once penetration levels surpass approximately $50 \%$. Additionally, while this analysis presents national average and marginal curtailment percentages for wind and PV combined, both curtailment measures can, and typically do, vary greatly across technologies and regions.
} 
have lower levels of average curtailment than the analogous scenarios with reference demand levels, particularly at or below $30 \%$ penetration levels, implying that the assumed flexibility of load associated with electrification helps mitigate curtailment to some extent. ${ }^{44}$

Another potential impact of high variable generation penetration is the reduced capacity value of some renewable technologies. With high electrification, our analysis suggests that firm capacity contributions are relatively less important due to reduction of the peak-to-average load ratios discussed previously. We did not identify other significant renewable grid integration challenges in our analysis, but further research is needed to assess system resource adequacy and reliability.

\section{Prices and System Costs}

As demand for electricity increases, additional investments in generation and transmission capacity and changes in system operation will impact power system costs and electricity prices. Specifically, we focus on wholesale electricity prices and $\mathrm{CO}_{2}$ allowance prices. We emphasize that the cost metrics we present are for the electricity sector only, meaning that the only costs represented are those associated with power sector capacity investment and operation. Notably, we exclude additional costs of electrifying end-use sectors, as well as the cost savings associated with reduced non-electricity fuel demand (e.g., gasoline for conventional vehicles and fossil fuel combustion for building space heating).

Electricity price results are shown for all scenarios in Figure 13. Prices, which are in dollars per megawatt-hour, are averaged both nationally and by decade for each scenario. The top panel shows "all-in" marginal cost-based electricity prices that represent the sum of individual component prices for energy, capacity, and all other components (e.g., ancillary services). The bottom panel contains average cost-based electricity prices.

\footnotetext{
${ }^{44}$ In addition to our assumption that vehicle demand does not impact peak hours, we allow load associated with hydrogen production to be fully flexible within a day-load for hydrogen production can be shifted to any period within a day, for example, from mid-day to overnight, as long as the total daily demand is met. This flexibility in load helps reduce curtailment by allowing load to be shifted to hours when surplus renewable generation would otherwise be curtailed. Additional opportunities for demand-side management or load flexibility in other sectors certainly exist and could be used to further reduce curtailment.
} 

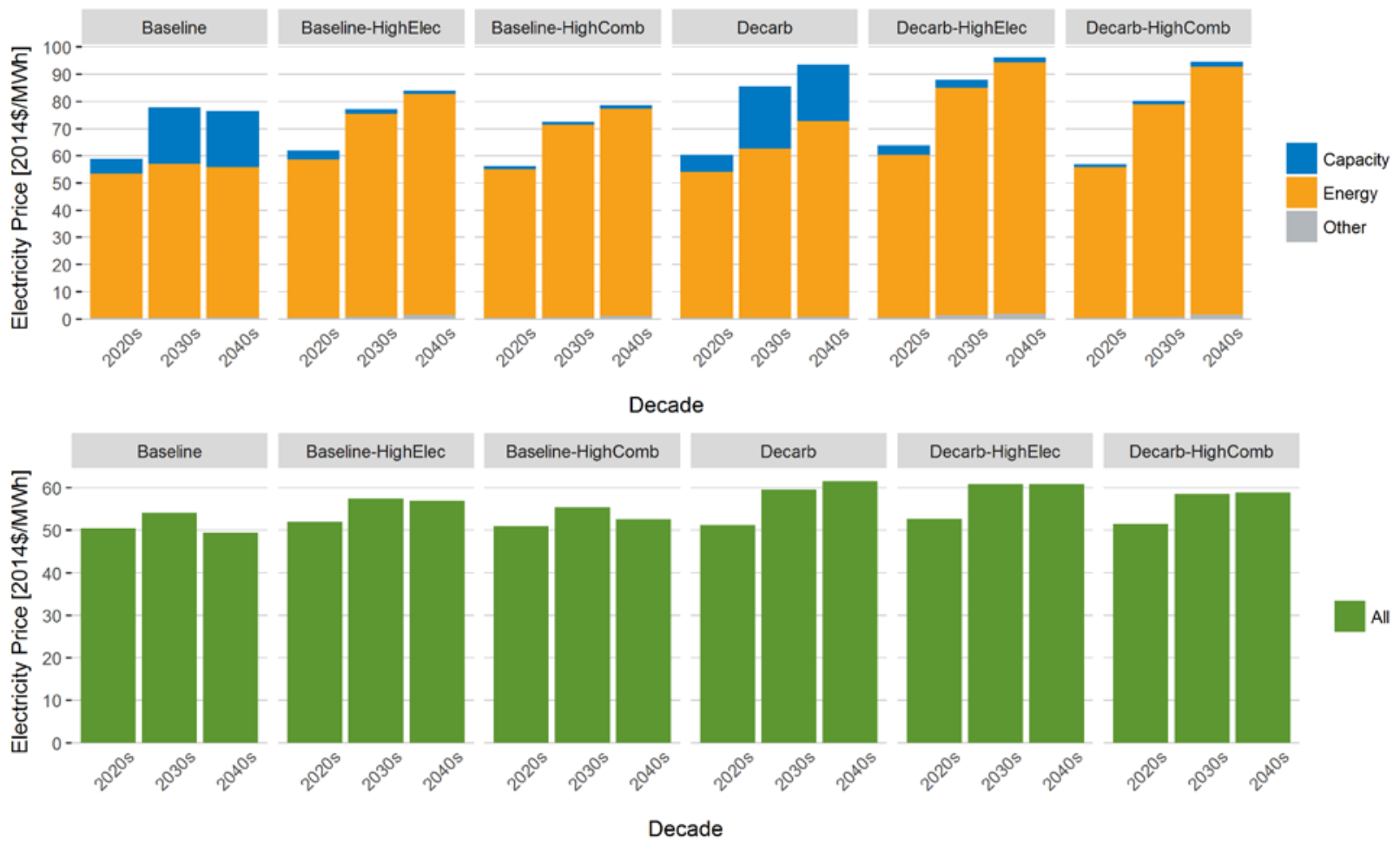

Figure 13. Marginal (top) and average (bottom) electricity prices by decade for all scenarios

The additional investment and changes in operation of the power system necessary to meet the increased demand from electrification drives electricity prices up. By the 2040s, both marginal and average prices increase by approximately $\$ 7 / \mathrm{MWh}$ (or $\$ 0.0073 / \mathrm{kWh}$ ) relative to the Baseline case, which represents a $10 \%$ increase in the marginal price and a $15 \%$ increase in the average price. When power sector decarbonization is also achieved, these price impacts are greater-marginal prices increase by almost $\$ 20 / \mathrm{MWh}(35 \%)$ and average prices by $\$ 11 / \mathrm{MWh}$ $(23 \%)$ relative to the Baseline case. However, the majority of this increase under the DecarbHighElec case is driven by the imposed carbon emissions cap. Electrification only accounts for $\$ 3 / \mathrm{MWh}$ of the $\$ 20 / \mathrm{MWh}$ increase in the marginal price over the Baseline case. Energy efficiency improvements mitigate these effects.

The marginal prices also demonstrate a key compositional difference across scenarios. For all scenarios in all decades, the largest component of the all-in price by far is the energy price. However, in the scenarios with reference demand, capacity prices make up much more significant portions of the all-in prices, particularly in the 2030s and 2040s. This is due to the fact that electricity load is much "peakier" under scenarios with reference demand (the Baseline and Decarb cases) than those with additional load from electrification - there are short periods of time during which total electricity load is far above the average load. Under scenarios with additional electrification load, load continues to exhibit peaks; however, relative to average load, the peaks are much less pronounced. As a result, the relative requirement for peak capacity and the associated capacity price is lower under the electrification scenarios. 
Power sector $\mathrm{CO}_{2}$ allowance prices (in dollars per ton) are presented in Figure $14 .{ }^{45}$ In most scenarios, these prices generally rise over time. In the Baseline scenario, however, the prices increase through the first several years of the CPP to $\$ 9$ per ton in 2028 and then steadily decline through 2046, at which point the policy, extended past 2030 in this analysis, becomes nonbinding.

When electrification is added to the Baseline scenario, the allowance price trajectories change quite a bit. For the Baseline-HighElec scenario, allowance prices increase rapidly in the first several years of the CPP, reaching $\$ 12$ per ton in 2026. They then increase steadily over the remainder of the time horizon, finishing at $\$ 22$ per ton in 2050. Recall that the CPP is represented as a mass-based policy, and therefore, emissions cannot exceed the 2030 mass targets. Under the electrification scenarios, even in the absence of a more stringent carbon policy, allowance prices increase because additional load must be met without increasing emissions. Efficiency improvements, not surprisingly, mitigate this effect by decreasing the amount of new load that must be met. Under the Baseline-HighComb scenario, allowance prices settle at approximately $\$ 10$ per ton $\mathrm{CO}_{2}$ below prices in the Baseline-HighElec scenario by 2050 .

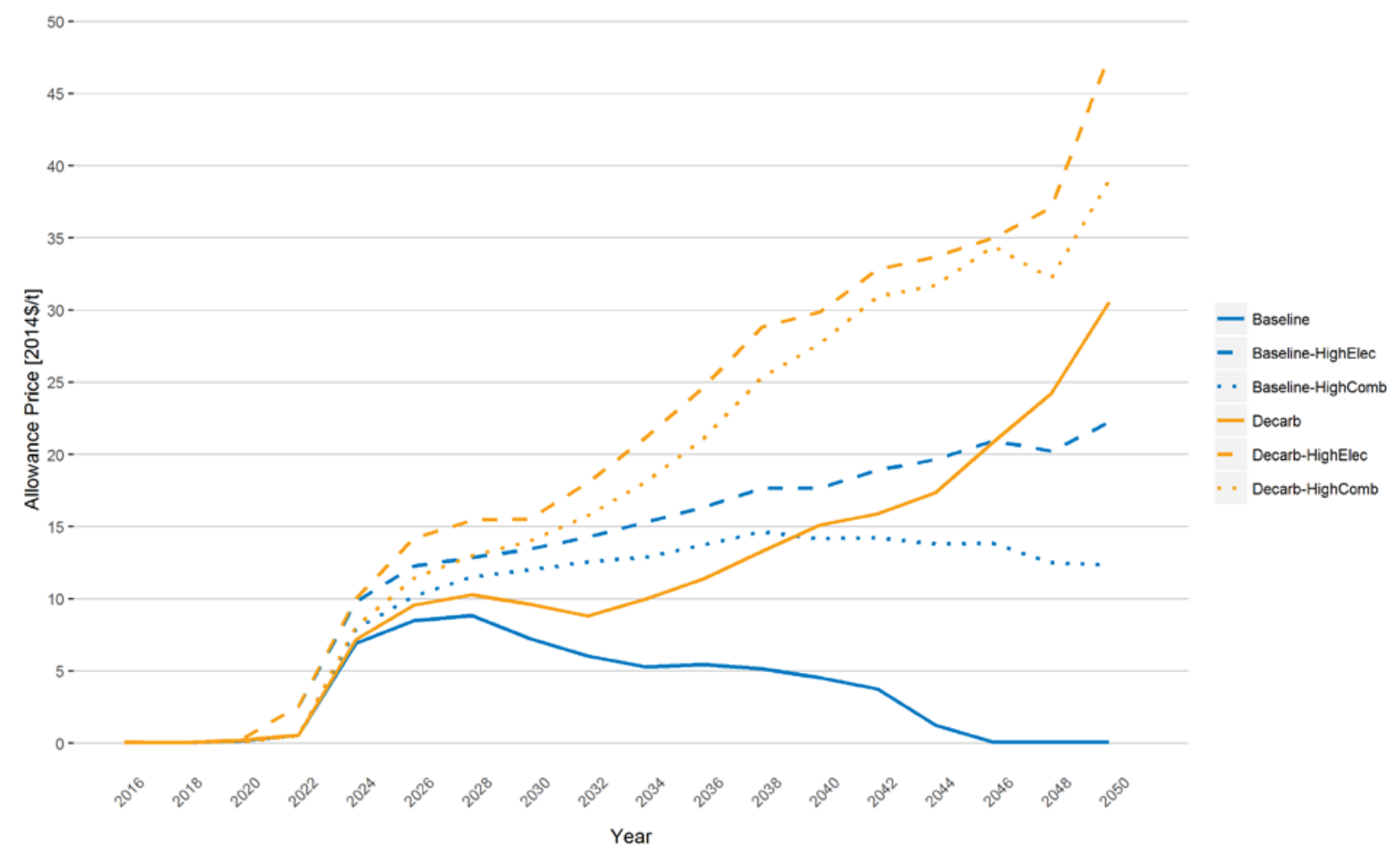

Figure 14. Carbon dioxide allowance prices over time for all scenarios

When the power sector achieves deeper levels of decarbonization beyond the CPP, allowance prices rise more rapidly, particularly beyond 2030. Prices in the Decarb scenario in particular diverge over time from the Baseline scenario, reaching $\$ 30$ per ton in 2050. Electrification in addition to decarbonization increases allowance prices further. In the absence of additional

\footnotetext{
${ }^{45}$ Emissions allowance prices are determined endogenously within the ReEDS model. The model assumes a market for emissions allowances and finds the equilibrium price within the power sector.
} 
efficiency improvements, allowance prices reach $\$ 48$ per ton in 2050 . Efficiency achieved in the Decarb-HighComb scenario reduces the 2050 allowance price to $\$ 39$ per ton.

These allowance prices demonstrate that even under scenarios of rapid growth in electricity consumption, the power sector has a wide set of options, namely renewable generation, coal-togas re-dispatch, CCUS, and nuclear generation that, in combination, can both meet the demand for electricity and reduce power sector emissions at relatively low-cost. However, it is important to note that these costs of GHG mitigation do solely reflect the power sector costs of meeting the CPP targets and the more stringent long-term power sector carbon mitigation targets modeled in the Decarb scenarios. They do not reflect the infrastructure investment outside of the power sector that would be required to achieve the widespread electrification examined in these scenarios.

\section{Integrated Energy and Emissions Implications}

Achieving the full electrification potential of end uses explored in the transportation, industry, and buildings sectors results in over a $72 \%$ reduction in fossil fuel combustion for these end uses by 2050 relative to the Baseline scenario - a reduction of approximately 33 quads of fossil fuel consumption. The transportation sector accounts for the large majority of this reduction (63\%), followed by buildings (31\%) and industry (the remaining 6\%). This decrease in fossil fuel consumption is accompanied by an increase in consumption of electricity of 5,700 TWh, equivalent to 19.5 quads of energy. This demonstrates that substituting conventional technologies with electric technologies leads to an overall increase in the final energy efficiency of end-use processes of over $40 \%$ - the same amount of energy services (e.g., light, process heat, personal transportation) are provided with $40 \%$ less final energy.

In order to meet the growing demand for electricity under the electrification scenarios, primary energy consumption in the power sector increases. However, this increase in primary energy is dominated by renewable energy sources; fossil usage in the power sector only increase by 8.7 quads in 2050 under the HighElec scenario, and by just 1.7 quads (composed entirely of natural gas) in the Decarb-HighElec. As a result, the decrease in end-use sector fossil consumption greatly outweighs the increase in power sector consumption.

Integrating across all sectors (end-use sectors and the power sector), electrification yields an overall net reduction of over 24 quads of fossil fuel consumption when electrification alone is pursued and a reduction of over 31 quads when electrification is pursued in conjunction with power sector decarbonization. ${ }^{46}$ When electrification is accompanied by efficiency improvements (HighComb case), fossil fuel consumption is reduced by an additional 6 quads for a total reduction of 30 quads. When electrification is accompanied by efficiency and decarbonization, the total reduction is 39 quads.

\footnotetext{
${ }^{46}$ Fossil fuel consumption in the end-use sectors decreases by 33 quads. Increases in fossil fuel consumption in the power sector depend on the policy representation: consumption increases approximately 9 quads when no additional emissions policy is present and by 2 quads when emissions are capped at $83 \%$ below the 2005 level. Net reductions in fossil fuel consumption are, thus, 24-31 quads per year by 2050.
} 
The substantial effect of electrification on fossil consumption, even in the absence of a long-term policy for emissions reduction in the power sector, is partially attributable to the CPP. As described above, compliance with the CPP is assumed to be achieved through a mass-based approach, and the final CPP targets are assumed to remain in place at their 2030 values through 2050. Given that the CPP extension is binding in all years under the scenarios with electrification, it creates an effective requirement that any additional electricity generated to serve incremental load must result in net-zero changes in emissions. Thus new load is met predominantly with a mix of NGCC (with emissions offsets from decreased coal generation), wind, and solar capacity.

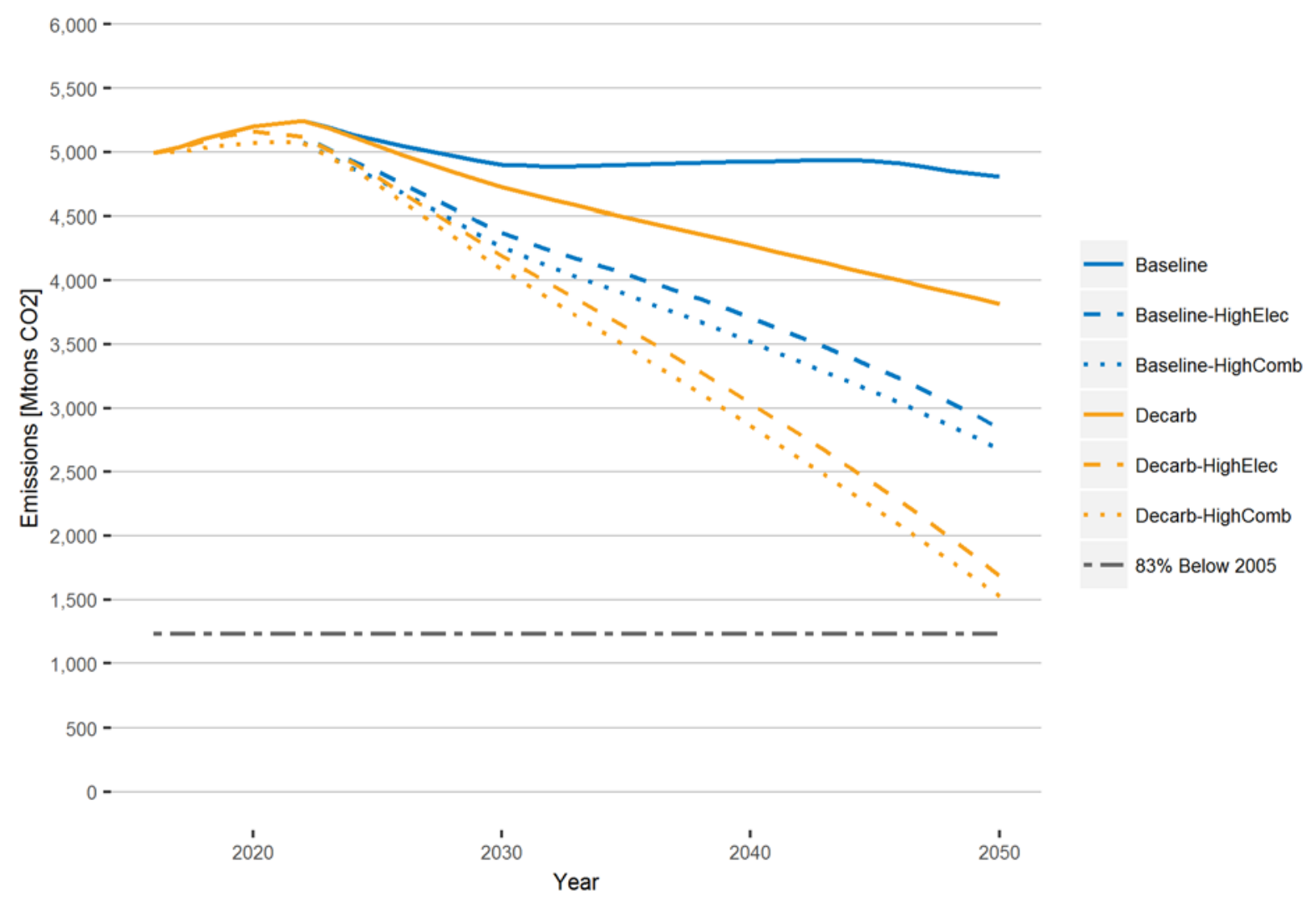

Figure 15. Projected carbon emissions from combustion of fossil fuels across all sectors and end uses analyzed

These reductions in fossil fuel usage have important implications for economy-wide emissions. Figure 15 shows the trajectory of total economy-wide combustion emissions across the six scenarios. The end uses explored in this analysis make up approximately $90 \%$ of economy-wide combustion-related $\mathrm{CO}_{2}$ emissions. Across the end uses explored, electrification in isolation of future additional emission reduction strategies results in a reduction of emissions of over $41 \%$ below the baseline level by 2050. Again this is partially driven by the extension of the CPP targets through 2050 in all cases, as the CPP drives a substantial reduction in the carbon intensity of generation (from approximately $0.3 \mathrm{t} \mathrm{CO}_{2}$ per MWh in 2030 to $0.14 \mathrm{t} \mathrm{CO}_{2}$ per $\mathrm{MWh}$ in 2050).

When electrification is coupled with deep decarbonization of the power sector, emissions reductions increase to almost $65 \%$ below the baseline level in 2050 (71\% below the 2005 level of 
fossil fuel combustion emissions). Increasing end-use efficiency can yield somewhat greater emissions reductions - the Decarb-HighComb case results in a 68\% reduction in emissions (74\% below the 2005 level of combustion emissions). Given that power sector emissions are limited by the CPP in the Reference case and by the $83 \%$ cap in the Decarbonization cases, reductions in the ultimate quantity of electricity demanded through efficiency have little impact on power sector emissions. The majority of the impact remains in the end-use sectors where some fossilfueled end-use technologies remain.

Although we demonstrate that coupled electrification and grid decarbonization can achieve substantial emissions reductions, the reductions fall short of an $83 \%$ economy-wide reduction below 2005 by 2050, particularly when non-combustion emissions are considered, which currently comprise approximately $1,650 \mathrm{Mt} \mathrm{CO}_{2}-\mathrm{e}$, or $24 \%$ of economy-wide emissions (EPA 2016a). As a result, in order for the United States to reach deep decarbonization goals, additional abatement strategies will need to be pursued. 


\section{Conclusions}

This initial analysis explored the potential for widespread electrification of end-use services and examined how achieving this potential while simultaneously decarbonizing the power sector could impact economy-wide energy consumption, emissions, and the future of the U.S. power system. We constructed a suite of scenarios under which end-use services in the buildings, transportation, and industrial sectors are rapidly electrified and, using a highly detailed model of the U.S. power sector, we explored how the power sector could evolve to meet the growing demand for electricity.

We find that widespread electrification in the buildings, transportation, and industrial sectors could lead to a doubling of electricity consumption by 2050 relative to a business-as-usual scenario. Despite this large increase in future electricity consumption, this represents an average annual growth rate of $2.6 \%$ - slightly lower than the growth rate during the last two decades of the $20^{\text {th }}$ century. Furthermore, we find that moderate increases in the energy efficiency of electric end-use devices have the potential to substantially reduce (by almost $50 \%$ ) the incremental load associated with electrification.

In order to meet the growing demand for electricity, significant amounts of new generation capacity would be required. This additional demand is met predominantly with new renewable (largely wind and solar PV) and NGCC capacity, and, to a lesser extent, increased generation from existing NGCC capacity. Furthermore, when electrification is pursued in concert with power sector decarbonization (emissions capped at $83 \%$ below 2005 levels in 2050), CCUS technologies also play an important role. By 2050 , approximately $50 \%$ of the total NGCC capacity online is coupled with CCUS technologies.

Despite the large growth in total electricity consumption and the associated increase in peak load, flexibility in incremental load (and opportunities for load shifting) serves to drive down the peak-to-average load ratio. In other words, the hourly load shape becomes smoother or less "peaky," and as a result, new generation resources are built largely for serving energy as opposed to meeting peak load requirements, increasing the overall efficiency of power system operation. This result stems from our assumption that the timing of load associated with hydrogen production (through electrolysis) is flexible and demonstrates the potential benefit (and perhaps need) to pursue opportunities to enable increased flexibility in loads, particularly in futures with widespread electrification.

Finally, electrification of end uses, particularly when coupled with power sector decarbonization, has the potential to substantially reduce economy-wide emissions of $\mathrm{CO}_{2}$ associated with fossil fuel combustion. Specifically, we find that electrification and simultaneous power sector decarbonization can achieve reductions up to $68 \%$ below the 2050 level under a business-asusual scenario or up to $74 \%$ below the 2005 level of fossil fuel combustion emissions. Furthermore, as a result of the current and expected future trend of decreasing carbon intensity of generation (driven by low-cost gas, declining costs of renewables, and policy support for clean energy), electrification alone can have a significant impact on GHG emissions. We find that electrification, in the absence of any additional power sector carbon policy, can result in a $41 \%$ reduction in fossil fuel combustion emissions. 
Given the significant potential to reduce emissions, electrification and decarbonization will be a key component to achieving a low-carbon future, but, in isolation, are not sufficient to achieve economy-wide GHG emissions reductions of $83 \%$ below the 2005 level. Thus, pathways to achieving deep reductions in GHG emissions will necessarily involve additional strategies for reduction such as substituting fossil fuels with biomass, hydrogen, or other low- or zero-carbon fuels, implementing industrial CCUS, and aggressively implementing energy efficiency measures.

Future work is needed to understand more comprehensively the role of all GHG abatement options because the analysis relies only on bounding electrification scenarios, generated using accounting tools and top-down analysis of energy-use projections. In particular, an assessment of the relative costs, benefits, and barriers of different future scenarios are needed to weigh merits of different actions and inaction. 


\section{References}

Ahman, Max, and Lars J Nilsson. 2015. "Decarbonizing Industry in the EU - Climate, Trade, and Industrial Policy Strategies." In Decarbonisation in the EU: Internal Policies and External Strategies, edited by Claire Dupont and Sebastian Oberthur. Basingstoke, Hampshire, United Kingdom: Palgrave MaxMillan.

Alexander, Marcus, et al. 2015. "Environmental Assessment of a Full Electric Transportation Portfolio." Electric Power Research Institute, Palo Alto, CA.

Bush, Brian, Marc Melaina, M. Penev, and W. Daniel. 2013. "SERA Scenarios of Early Market Fuel Cell Electric Vehicle Introductions: Modeling Framework, Regional Markets, and Station Clustering." Golden, CO: National Renewable Energy Laboratory.

California Air Resources Board. 2012a. "Scenario Assumptions and Results." Vision for Clean Air: A Framework for Air Quality and Climate Planning.

California Air Resources Board. 2012b. "Scenario Assumptions and Results." Vision for Clean Air: A Framework for Air Quality and Climate Planning.

California Air Resources Board. 2015a. "Technology Assessment: Medium- and Heavy-Duty Battery Electric Trucks and Buses."

California Air Resources Board. 2015b. "Technology Assessment: Medium- and Heavy-Duty Fuel Cell Electric Vehicles."

California Air Resources Board. 2015c. "Technology Assessment: Medium- and Heavy-Duty Fuel Cell Electric Vehicles."

CEMBUREAU. 2013. "The Role of Cement in the 2050 Low Carbon Economy." European Cement Association, Brussels.

Choate, William. 2003. "Energy and Emission Reduction Opportunities for the Cement Industry." Columbia, MD: BCS, Incorporated.

Clarke, Leon, Alan Fawcett, John Weyant, James McFarland, Vaibhav Chaturvedi, and Yuyu Zhou. 2014. "Technology and U.S. Emissions Reduction Goals: Results of the EMF 24 Modeling Exercise." The Energy Journal 9-31.

Cole, Wesley, Haley Lewis, Ben Sigrin, Robert Margolis. 2016a. Interactions of Foogtop PV Deplopyment with the Capacity Expansion of the Bulk Power System. Applied Energy (168): 473-481.

Cole, Wesley, et al. 2016b. "2016 Standard Scenarios: A U.S. Electricity Sector Outlook." Golden, CO: National Renewable Energy Laboratory.

Crawley, Drury, et al. 2001. "EnergyPlus: Creating a New-Generation Building Energy Simulation Program." Energy and Buildings (33): 319-31.

Davis, Stacy, Susan Williams, and Robert Boundy. 2016. "Transportation Energy Data Book: Edition 35." Oak Ridge, TN: Oak Ridge National Laboratory.

den Boer, Eelco, et al. 2013. "Zero Emissions Trucks.” Delft: CE Delft

Deru, Michael, et al. 2011. "U.S. Department of Energy Commercial Reference Building Models of the National Building Stock." Golden, CO: National Renewable Energy Laboratory.

DOE. 2017. Quadrennial Energy Review 1.2. Washington, D.C.: United States Department of Energy.

DOE. 2015a. "Bandwidth Study on Energy Use and Potential Energy Saving Opportunities in U.S. Iron and Steel Manufacturing." Washington, D.C.: Office of Energy Efficiency and Renewable Energy, U.S. Department of Energy. 
DOE. 2015b. "Bandwidth Study on Energy Use and Potential Energy Saving Opportunities in

U.S. Petroleum Refining." Washington, D.C.: Office of Energy Efficiency and

Renewable Energy, U.S. Department of Energy.

DOE. 2015c. "Bandwidth Study on Energy Use and Potential Energy Saving Opportunities in

U.S. Pulp and Paper Manufacturing." Washington, D.C.: Office of Energy Efficiency and

Renewable Energy, U.S. Department of Energy.

DOE. 2015d. "Bandwidth Study on Energy Use and Potential Energy Saving Opportunities in

U.S. Chemical Manufacturing." Washington, D.C.: Office of Energy Efficiency and

Renewable Energy, U.S. Department of Energy.

DOE. 2015e. Quadrennial Technology Review: An Assessment of Energy Technologies and

Research Opportunities. Washington, D.C.: United States Department of Energy.

DOE. 2014. "EV Everywhere Grand Challenge." Washington, D.C.: Department of Energy

Office of Energy Efficiency and Renewable Energy.

DOE. 2013. "Clean Cities Guide to Alternative Fuel and Advanced Medium- and Heavy-Duty

Vehicles." Golden, CO: Prepared by the National Renewable Energy Laboratory for the

U.S. Department of Energy, Office of Energy Efficiency and Renewable Energy.

DOE. 2007a. "Mining Industry Energy Bandwidth Study." Washington, D.C.: Industrial

Technologies Program, U.S. Department of Energy.

DOE. 2007b. "U.S. Energy Requirements for Aluminum Production: Historical Perspective,

Theoretical Limits, and Current Practices." Washington, D.C.: Industrial Technologies

Program, U.S. Department of Energy.

EIA. 2009. Residential Energy Consumption Survey. Washington, D.C.: United States

Department of Energy, Energy Information Administration.

EIA. 2013. 2010 Manufacturing Energy Consumption Survey Data. Washington, D.C.: United

States Department of Energy, Energy Information Administration.

EIA. 2015. "The 2015 Annual Energy Outlook." Washington, D.C.: Energy Information

Administration, Department of Energy.

Elgowainy, A, et al. 2010. "Well-to-Wheels Analysis of Energy Use and Greenhouse Gas

Emissions of Plug-In Hybrid Electric Vehicles." Chicago, IL: Argonne National

Laboratory.

EOP/CEQ. 2016. United States Mid-Century Strategy for Deep Decarbonization. Washington,

D.C.: United States Executive Office of the President, Council on Environmental Quality.

EPA. 2016a. Inventory of U.S. Greenhouse Has Emissions and Sinks: 1990-2014. Washington,

D.C.: U.S. Environmental Protection Agency.

EPA. 2016b. Population and Activity of On-Road Vehicles in MOVES2014. Washington, D.C.:

U.S. Environmental Protection Agency.

EPA. 2015. MOVES2014a User Guide. Washington, D.C.: United States Environmental

Protection Agency, Assessment and Standards Division, Office of Transportation and Air Quality, EPA.

EPRI. 2010. Electrotechnology Reference Guide, 2010. Palo Alto, CA: Electric Power Research Institute (EPRI).

Eurek, Kelly, et al. 2016. "Regional Energy Deployment System (ReEDS) Model

Documentation: Version 2016." Golden, CO: National Renewable Energy Laboratory.

Frew, Bethany, et al. 2016. "Utility-Scale Solar Deployment Scenarios of the Western United

States: Implications for Solar Energy Zones in Nevada." Golden, CO: National

Renewable Energy Laboratory. 
Greenblatt, Jeffery, Max Wei, and James McMahon. 2012. California's Energy Future:

Buildings \& Industrial Efficiency. Sacramento, CA: California Council on Science and Technology.

ICF and E3. 2014. "California Transportation Electrification Assessment." San Francisco, CA:

ICF International, and Energy \& Environmental Economics.

IHS Inc. 2016. "Vehicle Market Analysis: Registrations and Vehicles-in-Operation." Automotive Industry Market Performance Data and Analysis.

IEA. 2011. Technology Roadmap: Energy-Efficiency Buildings: Heating and Cooling Equipment. Paris, France: International Energy Agency.

Laitner, John (Skip), Steven Nadel, R. Neal Elliot, Harvey Sachs, and A. Siddiq Khan. 2012. The Long-Term Energy Efficiency Potential: What the Evidence Suggests. Washington, D.C.: American Council for an Energy-Efficient Economy (ACEEE).

Lantz, Eric, et al. 2016. "Implications of a PTC Extension on U.S. Wind Deployment." Golden, CO: National Renewable Energy Laboratory.

MacDonald, Alex, Christopher Clack, Anneliese Alexander, Adam Dunbar, James Wilczak, and Yuanfu Xie. 2016. "Future Cost-Competitive Electricity Systems and their Impact on US CO2 Emissions." Nature 6 526-31.

Mai, Trieu, et al. 2016. "Impacts of Federal Tax Credit Extensions on Renewable Deployment and Power Sector Emissions." Golden, CO: National Renewable Energy Laboratory.

Mai, Trieu, et al. 2016. "A Prospective Analysis of the Costs, Benefits, and Impacts of U.S. Renewable Portfolio Standards." Golden, CO: National Renewable Energy Laboratory.

Mai, Trieu, et al. 2014. "Renewable Electricity Futures for the United States." IEEE Transactions on Sustainable Energy 5(2): 372-78.

Mauer, Joanna, Andrew deLaski, Steven Nadel, Anthony Fryer, and Rachel Young. 2013. "Better Appliances: An Analysis of Performance, Features, and Price as Efficiency has Improved." Washington, D.C.: American Council for an Energy-Efficient Economy and Appliance Standards Awareness Project.

McLaren, Joyce, John Miller, Eric O'Shaughnessy, Eric Wood, and Evan Shapiro. 2016. Emissions Associated with Electric Vehicle Charging: Impact of Electricity Generation Mix, Charging Infrastructure Availability, and Vehicle Type. Golden, CO: National Renewable Energy Laboratory.

Melaina, Marc, et al. 2016. "National Economic Value Assessment of Plug-In Electric Vehicles: Volume 1." Golden, CO: National Renewable Energy Laboratory (NREL).

Melaina, Mark, et al. 2013. "Transportation Energy Futures Series: Alternative Fuel Infrastructure Expansion: Costs, Resources, Production Capacity, and Retail Availability for Low-Carbon Scenarios." Washington, D.C.: United States Department of Energy.

Mignone, Bryan, et al. 2013. "Cost-effectiveness and Economic Incidence of a Clean Energy Standard." Economics of Energy \& Environmental Policy 1(3): 59-86.

NAS. 2010. Real Prospects for Energy Efficiency in the United States. National Academy of Sciences, Washington, D.C.: The National Academies Press.

National Research Council. 2013. Transitions to Alternative Vehicles and Fuels. National Academy of Sciences, Washington, DC: National Academies Press.

Neubauer, J. 2014. "Battery Lifetime Analysis and Simulation Tool (BLAST) Documentation." Golden, CO: National Renewable Energy Laboratory.

NREL. 2016. Annual Technology Baseline. Golden, CO: National Renewable Energy Laboratory (NREL). 
Plotkin, Steve, Thomas Stephens, and Walter McManus. 2013. "Transportation Energy Futures Series: Vehicle Technology Deployement Pathways: An Examination of Timing and Investment Constraints." Washington, D.C.: United States Department of Energy.

Rue, David, James Servaites, and Warren Wolf. 2007. "Industrial Glass Bandwidth Analysis." Des Plaines, IL: Gas Technology Institute.

Short, Walter, et al. 2011. "Regional Energy Deployment System (ReEDS)." Golden, CO: National Renewable Energy Laboratory.

Silver, Fred, and Tom Brotherton. 2013. "CalHEAT Research and Market Transformation Roadmap for Medium- and Heavy-Duty Trucks." Pasedena, CA: California Hybrid, Efficient and Advanced Truck Research Center.

Stephens, Thomas. 2013. "Transportation Energy Futures Series: Non-Cost Barriers to Consumer Adoption of New Light-Duty Vehicle Technologies." Washington, D.C.: United States Department of Energy.

Wei, Max, et al. 2013. "Deep Carbon Reductions in California Require Electrification and Integration Across Economic Sectors." Environmental Research Letters 1-10.

Williams, James, et al. 2014. Pathways to Deep Decarbonization in the United States. San Francisco, CA: Energy and Environmental Economics, Inc.

WSP Parsons Brinckerhoff. 2015. "Industrial Decarbonisation \& Energy Efficiency Roadmaps to 2050: Cross-Sector Summary." London, UK: WSP Parsons Brinckerhoff.

Zhou, Yan, and Anant Vyas. 2014. "VISION Model Description and User's Guide: Model Used to Estimate the Impacts of Highway Vehicle Technologies and Fuels on Energy Use and Carbon Emissions to 2100." Chicago, IL: Argonne National Laboratory. 


\section{Appendix. Detailed Methods for Electrification Potential Estimates and Development of the Hourly Load Profiles}

\section{Residential and Commercial Buildings}

As summarized in the Methods section, the electrification potential estimates for 2020-2050 were developed using national annual end-use service and fuel consumption projections from the EPSA Base Case simulated using the NEMS model. The EPSA Base Case includes projections of fuel and service consumption from present day to 2040. Projections were extended through the 2041-2050 period using a linear trend from 2030 to 2040. The end-use service demand categories represented within the NEMS model are shown in Table A-1.

Table A-1. Residential and Commercial End-Use Services Represented in the NEMS Model ${ }^{\mathrm{a}}$

\begin{tabular}{|l|l|}
\hline Residential & Commercial \\
\hline Space Heating & Space Heating \\
Space Cooling & Space Cooling \\
Water Heating & Water Heating \\
Refrigeration & Ventilation \\
Cooking & Cooking \\
Clothes Dryers & Lighting \\
Freezers & Refrigeration \\
Lighting & Office Equipment (PC) \\
Clothes Washers & Office Equipment (non-PC) \\
Dishwashers & Other Uses \\
Televisions and Related & \\
Equipment & \\
Computers and Related & \\
Equipment & \\
Furnace Fans and Boiler & \\
Circulation Pumps & \\
Other Uses & \\
\hline
\end{tabular}

${ }^{a}$ End uses with significant potential for electrification are shown in bold italics.

In both the residential and commercial sectors, end uses selected for electrification were space heating, water heating, and cooking, as well as end uses included in the "other" category, such as pool and hot-tub heaters, outdoor grills, and motorized devices (e.g., lawn mowers). With the exception of space heating, we assume that all of the end uses linearly ramp from their businessas-usual 2020 fuel mix to $100 \%$ electricity-fueled by 2050 . We assume that electrification of space heating does not begin until 2025, but electric heating devices (both heat pumps and resistance heaters) are subsequently adopted at a rate sufficient to achieve $100 \%$ electrification of space heating by 2050. The fuel mix resulting from these assumed electrification rates dictate the 2020-2050 national annual estimates of electricity and fuel consumption by end use.

In order to input our annual electricity consumption projections into the ReEDS model, we must disaggregate the projections along both spatial and temporal scales. Ultimately, we disaggregate 
our projections of electricity consumption by year and end use to electricity consumption by year, hour, state, and end use. Disaggregation from national- to state-level projections is based on EIA's RECS and CBECS, as well as data from EIA's State Energy Data System (SEDS). ${ }^{47}$ Disaggregation to hourly data (by state) is based on detailed bottom-up simulations of building energy consumptions using the EnergyPlus model (Crawley et al. 2001).

The RECS provides state-level consumption of energy by fuel type and end use. From this data, we calculated the state share (or state fraction) of national energy consumption (aggregated across fuels) by end use. We then applied these shares to the national projections to yield statelevel projections of electricity consumption by end use.

The CBECs data only provide end-use consumption values at the census region level. Thus, for the commercial buildings, electrification scenario estimates were first disaggregated to the census level. We then disaggregated the census-level projections to the state level by applying the state fraction of 2012 total census-level consumptions based on the EIA SEDS data.

In order to create annual hourly load profiles by state and end use for each subsector, we relied on a large set of individual building-level simulations carried out using the EnergyPlus model. For the residential sector, hourly energy consumption by fuel and end use was simulated for a representative single-family detached household at 216 typical meteorological year locations across the continental United States. Figure A-1 shows the locations of the simulated households.

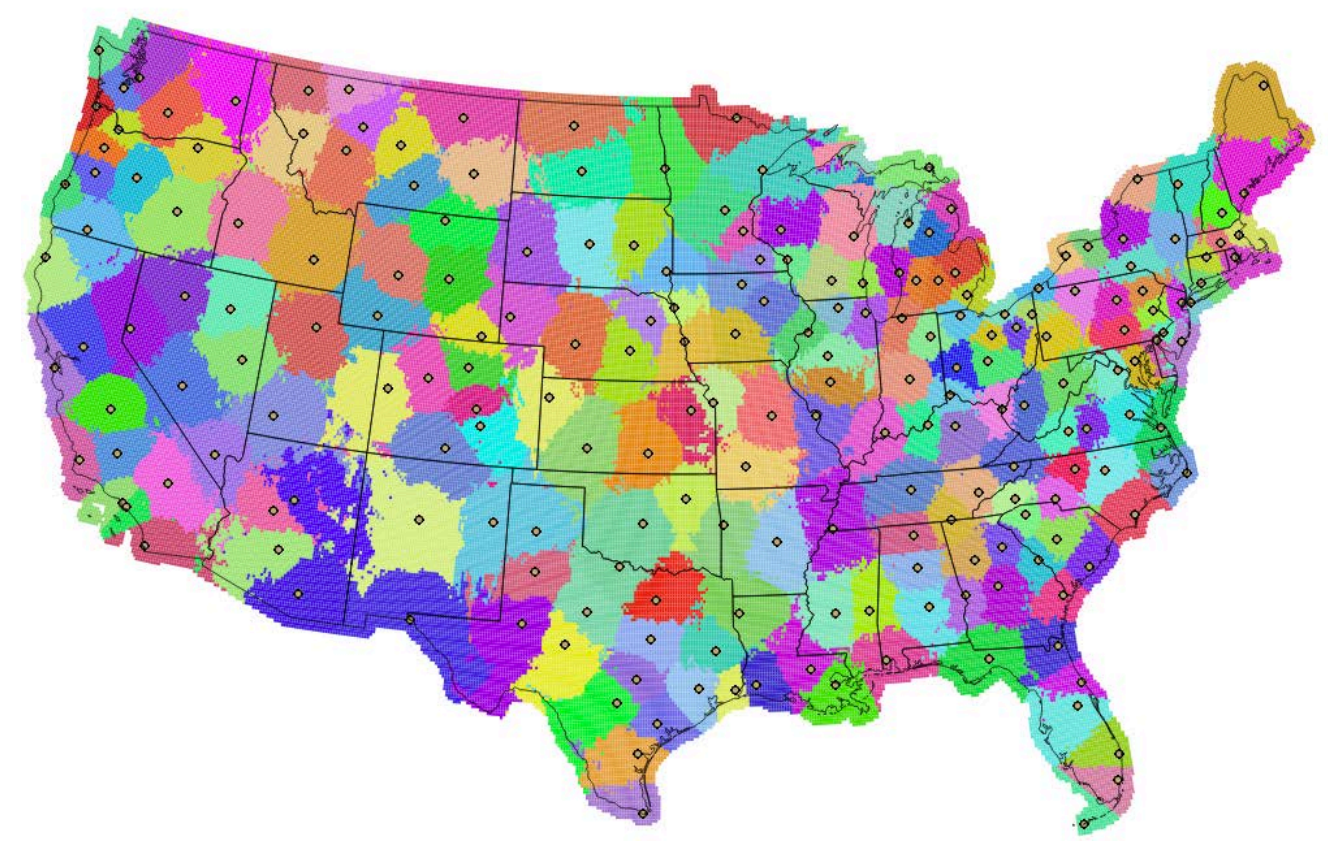

Colored regions depict the areas covered by each typical meteorological year region.

Figure A-1. Locations of the representative households simulated using the EnergyPlus model

\footnotetext{
${ }^{47}$ RECS \& CBECS: http://www.eia.gov/consumption/data.php\#rec SEDS: http://www.eia.gov/state/seds/seds-data-complete.cfm?sid=US\#Consumption
} 
For each end use, we then converted these hourly demands into an hourly index such that the value for each hour represented the hourly fraction of the total annual consumption for that particular end use. Finally, to create state-level load profile indices by end use, we averaged the end-use indices from each location within a state, weighted by the total number of households that each location represented within the state. These state-level hourly end-use indices were then applied to the state-level annual projections of end-use electricity consumption to yield electricity consumption by state, year, hour, and end use.

For commercial buildings, hourly energy consumption by fuel and end use was modeled for a set of 90 different DOE commercial building types and vintages (15 building types and 6 different vintages) in each of 16 different American Society of Heating, Refrigerating and Air-

Conditioning Engineers (ASHRAE) climate zones (Deru et al. 2011). ${ }^{48}$ This resulted in a total of 1,440 simulations of building type, vintage, and climate sets. Hourly outputs for each simulation were normalized on a square-footage basis, which yielded hourly energy demand by fuel and end use per unit area (square foot) of each set. We then calculate state-level hourly demand by multiplying the area-normalized end-use consumption for each set (type, vintage, and climate) by the total square footage of each set in each state and aggregate across sets and within states.

\section{Transportation}

To develop annual estimates of energy consumption from the transportation sector, we created a modified version of ANL's VISION model (Zhou and Vyas 2014). VISION is a spreadsheet tool that relies on exogenous user inputs, such as vehicle market penetration and efficiency over time, and calculates outputs, such as energy use by fuel type, oil use, and carbon emissions. ${ }^{49}$ As part of the calculations, VISION tracks vehicle stock turnover and vehicle miles traveled based on assumptions derived from vehicle survival data and age-dependent usage characteristics. We base our modified version on the 2015 default version of VISION, which relies on the EIA's 2015 AEO scenarios and, implicitly, the transportation module of NEMS used in developing those scenarios (EIA 2015).

The representation of LDVs in our modified model is identical to the default VISION model. The model represents a suite of 13 LDV types for both cars and light trucks (26 total): three types of PHEVs, two types of BEVs, three types of hybrid electric vehicles (HEVs), and an individual type each for FCVs, compressed natural gas vehicles, E-85 flex fuel vehicles, and conventional diesel and gasoline vehicles. The multiple types of PHEVs, BEVs, and HEVs comprise different electric-range options and differentiate between gasoline and diesel vehicles for the hybrid vehicles. While electric drive range certainly impacts vehicle costs, consumer adoption, and infrastructure needs, these important factors do not have material impacts on our top-down analysis where market penetration is prescribed. These details also do not have material first-order impacts on electricity consumption, energy use, and GHG implications that are the core focus of our analysis.

\footnotetext{
${ }^{48}$ Building types modeled include: small office, medium office, large office, warehouse, hospital, outpatient hospital, primary school, secondary school, quick-service restaurant, full-service restaurant, mid-rise apartment, small hotel, large hotel, retail standalone, and retail strip mall. Six vintages of each building type were modeled: pre1980, 1980-2004, 2005-2006, 2007-2009, 2010-2012, and 2013 or later.

${ }^{49}$ While the VISION model is designed to conduct analysis to the year 2100 , we focus on results through 2050 only.
} 
For M/HDVs, we expand the default VISION model to include 16 total vehicle types: 6 class $3-$ 6 vehicle types and 10 vehicles types for class 7-8 trucks. The default version of VISION has nine different vehicle types, including four types (conventional gasoline and diesel, natural gas, and HEV diesel) for class 3-6 trucks and five types (single unit and combination conventional, single unit and combination natural gas, and single unit HEV) for larger class 7-8 trucks. ${ }^{50}$ However, it does not represent BEV or FCV options for M/HDVs of any class and does not represent an HEV diesel option for class 7-8 combination trucks. As such, we create seven additional vehicle categories in our version of the model to represent those options for the medium and heavy-duty fleet. Specifically, we add a combination HEV diesel category and class 3-6 and class 7-8 (both single-unit and combination) BEV and FCV categories.

Incorporating additional vehicle categories into the analysis requires assumptions on those vehicles' survival rates, usage, and reference fuel economy. Consistent with the default VISION model approach for the LDV fleet, we apply the existing survival rates for conventional $\mathrm{M} / \mathrm{HDV}$ s to our new categories (in the default model, survival rates are specific to the broad vehicle categories - cars, light-duty trucks, class 3-6 trucks, class 7-8 single-unit trucks, and class 7-8 combination trucks - but do not differentiate within those categories). For vehicle usage, we construct age-specific vehicle miles traveled, such that total usage is held fixed across all scenarios. Finally, we assume that medium- and heavy-duty BEV and FCV have fuel economies of three- and two-times conventional diesel vehicles, respectively, which matches the assumptions from the California Air Resources Board's initial version of the VISION model (California Air Resource Board 2012).

Of course, our analysis depends critically on assumptions regarding vehicle technology deployment and fuel efficiency improvements over time. Under our HighElec and HighComb scenarios, we prescribe a different market penetration trajectory wherein sales of conventional vehicles phase out and are replaced by PHEVs, BEVs, and FCVs. ${ }^{51}$ Our assumptions for the light- and medium/heavy-duty penetration levels are as follows:

- Light-duty vehicles - We assume increasing market penetration of EVs and FCVs in the LDV market through 2050. For the EVs, we assume that PHEVs serve as a bridge technology between conventional vehicles and BEVs as their share of new sales increases from 2015 to 2030 and decreases thereafter until reaching zero in 2050; the role of HEVs is similar, although their share of new sales begins to decrease after 2020 and phases out by $2040 .^{52}$ Likewise, we assume zero sales for conventional vehicles from 2040 to 2050. By 2050, we assume that all new passenger vehicle sales are BEVs and all new light-duty truck sales are split evenly between BEVs and FCVs.

- Medium- and Heavy-duty vehicles - Similar to the LDV market, we assume increasing market penetrations of EVs and FCVs in the M/HDV market through 2050. We assume

\footnotetext{
${ }^{50}$ The modeled fuel types in VISION include multiple options for natural gas and biodiesel.

${ }^{51}$ Although they do not contribute to electrification by drawing energy from the grid, we also assume increased penetration of HEVs relative to the Reference scenario.

52 Our treatment of PHEVs in this scenario is similar to that described in the scenario analysis of the California Air Resources Board's "Vision for Clean Air: A Framework for Air Quality and Climate Planning" (California Air Resources Board 2012).
} 
that all new sales in 2050 are either BEVs or FCVs. However, there are a few important distinctions in our treatment of the M/HDV market. First, we assume that EVs and FCVs enter the market much more gradually than they do for LDVs. ${ }^{53}$ Second, we base our relative shares of sales for class 3-6 and class 7-8 BEVs and FCVs on projected proportions of vehicles within each category used for short-haul and long-haul applications. ${ }^{54}$ We assume that BEVs are adopted for short-haul applications, while FCVs are adopted for long-haul applications. ${ }^{55}$ Class 3-6 trucks are predominantly used for short-haul purposes (short-haul makes up 97\% of class 3-6 applications), and therefore, by $2050,97 \%$ of sales of class 3-6 vehicles are BEVs. Class 7-8 trucks are more evenly split between short- and long-haul applications, and thus $53 \%$ of sales of class 7-8 trucks are BEVs by 2050

Our analysis is restricted to the above-described on-road vehicles. Other transportation demand, such as in aviation, marine, and rail, are excluded from our electrification potential estimates. While electrification might be a viable option to serve these other transport needs, detailed research on the plausibility and costs for such a transformation is more limited. ${ }^{56}$ On-road vehicles dominate transport-related GHG emissions and energy use (84\% in 2014), so the omission of non-road electrification likely has a relatively minor impact on our overall electrification potential and GHG emission estimates.

Like the default version of VISION, our version of the model is resolved at the aggregate annual and national levels; however, our power sector analysis using ReEDS requires temporal (seasonal and diurnal) and regional disaggregation. To perform the disaggregation, we rely on methodologies developed in the National Economic Value Assessment (NEVA) of Electric Vehicles study (Melaina et al. 2016). The goal of the NEVA study is to assess the potential benefits and costs for the large-scale, nationwide implementation of EVs and infrastructure to support those vehicles out to 2035. Time-resolved charging profiles were developed for the NEVA study using the Battery Lifetime Analysis and Simulation Tool for Vehicles (BLAST-V) (Neubauer 2014). BLAST-V calculates the energy consumption and travel limitations for EVs

\footnotetext{
${ }^{53}$ We base this assumption on the relative lack of current commercial applications of BEVs and FCVs in the HDV space. Although numerous studies have identified these types of vehicles as viable options in the future (National Renewable Energy Laboratory 2013; Silver and Brotherton 2013; den Boer et al. 2013), more development is required in order to make them viable for any significant market penetration level. For reviews of the current state of heavy-duty BEVs and FCVs, see (California Air Resources Board 2015a; California Air Resources Board 2015b) and (California Air Resources Board 2015c), respectively.

${ }^{54}$ These shares are derived using the default source type and regulatory class count and fraction data from the EPA's MOVES model (EPA 2016b). The source types can be used to differentiate between short-haul and long-haul vehicles as well as single-unit and combination vehicles. Regulatory classes can be used to differentiate vehicles by class.

${ }^{55}$ This assumption is based on the limited range characteristics of BEVs and is supported by (den Boer et al. 2013) and (California Air Resources Board 2015b), which discuss the technological benefits to fuel cell over battery electric powertrains in heavy-duty long-haul applications. Regarding short-haul applications, (Silver and Brotherton 2013) assert that "the torque characteristics of electric motors are well-suited for moving heavy loads, as evidenced by their long use in freight trains, and suggest that the upper limits of their power capabilities will not be tested in trucks" (p. 38). Based on this information, we assume that BEVs can be used for all short-haul applications, regardless of vehicle weight.

${ }^{56}$ ICF and E3 (2014) assesses transportation electrification options for a wide range of modes for California, but no immediate methodology exists for extrapolating these estimates nationwide.
} 
using trip-level data along with climate, vehicle, and driver data. ${ }^{57}$ The temporal disaggregation also relies on vehicle trip data from the National Household Travel Survey (2009) along with climate and vehicle characteristic data. The Scenario Evaluation and Regionalization Analysis (SERA) model (Bush et al. 2013) was also used in the NEVA study (National Renewable Energy Laboratory 2016). While the SERA model was used extensively in NEVA, for our purposes we primarily rely on the SERA model for regionalized computations of vehicle usage to the zip-code level. It accomplishes this using household and vehicle registration data.

Together, the resulting spatial output from the SERA model along with the temporal output from BLAST-V from the NEVA study are used to spatially and temporally disaggregate the electricity consumption resulting from our vehicle deployment scenarios. In particular, the charging profiles and regional distributions developed in NEVA are normalized and used for the LDV fleet and are scaled to match the required national electricity consumption from our scenarios. ${ }^{58}$ For the medium- and heavy-duty vehicle fleet, existing charging profiles are used for temporal disaggregation, and vehicle registration data from the Polk database are used for regional disaggregation (IHS Inc. 2016). The resulting profiles are scaled to match electricity consumption from the vehicle deployment scenarios. ${ }^{59}$ These disaggregated electricity consumption estimates are used as inputs into the ReEDS model for the electric-sector analysis.

Hydrogen production for use in FCVs can also impact electric infrastructure needs as well as primary energy use and GHG emissions. Various hydrogen production pathways can have significantly different implications across these metrics. While acknowledging the wide range of possible outcomes depending on hydrogen pathways, we apply an admittedly simple assumption where electrolysis is used for all hydrogen production needed for the estimated FCVs. This assumption helps maintain self-consistency in our energy and GHG accounting in that the required energy and GHG emissions for hydrogen production are embedded in the - (ReEDS) analysis. As a result of this assumption and all else being equal for fuel economy and vehicle adoption, the electricity demand for transportation reflects an upper bound. However, we assume the timing (but not the location) of hydrogen production is determined endogenously within the ReEDS model to reflect some of the storage and infrastructure advantages of FCVs over BEVs or PHEVs.

\section{Industry}

As summarized in the main body of the report, projections of the change in electricity consumption resulting from the electrification of boilers and process heat production were developed at the national level based on projected energy consumption by fuel type and end use from the EPSA NEMS Base Case. Electrification potential was estimated based on the use of six

\footnotetext{
${ }^{57}$ Electricity consumption patterns depend strongly on vehicle types (including vehicle range and battery size), charging configurations and infrastructure, and rate structures. These issues are beyond the scope of the current analysis but are discussed in the NEVA study. For our purposes, we rely on the assumptions from NEVA, which include a wide mix of EVs and charging configurations. In particular, NEVA assumed a combination of home, work, and public charging; charger types (e.g., level 1 and level 2 chargers); and an equal mixture of opportunity charging and timed charging.

${ }^{58}$ NEVA study charging profiles are selected to match the vehicles considered in the current study (BEV100 and $200=$ NEVA BEV70, and 140, PHEV10 and 40 = NEVA PHEV15, and 40).

${ }^{59}$ NEVA study charging profiles are selected to match the vehicles considered in the current study $(\mathrm{BEV}=\mathrm{BEV} 140)$.
} 
technologies in seven industries. Annual growth rates of these technologies were identified for 2017-2020 and 2021-2050 (Table A-2). Growth rates estimated by EPRI (EPRI 2010) were assumed for the 2017-2020 period. It was assumed that these technologies completely electrify their relevant industry end uses by 2050, with the exception of direct arc melting in the iron and steel sector. Consequently, the constant annual growth rates assumed for 2021-2050 are the equivalent electricity growth rates required to completely displace fuel combustion use by 2050 for the applicable industry and end uses.

Table A-2. Assumed Growth Rates of Electrotechnologies in Their Applicable Industries and by End Use

\begin{tabular}{lllll}
\hline Electrotechnology & Industry & End Use & $\begin{array}{l}\text { Annual Growth } \\
\text { Rate }(2017- \\
2020)\end{array}$ & $\begin{array}{l}\text { Annual Growth } \\
\text { Rate (2021- } \\
2050)\end{array}$ \\
\hline Electrolytic reduction & $\begin{array}{l}\text { Nonferrous } \\
\text { metals, excluding } \\
\text { aluminum }\end{array}$ & $\begin{array}{l}\text { Process } \\
\text { heating }\end{array}$ & $7.0 \%$ & $3.4 \%$ \\
\hline Metal fabrication & $\begin{array}{l}\text { Process } \\
\text { heating }\end{array}$ & $2.4 \%$ & $5.5 \%$ \\
\hline Electric boilers & $\begin{array}{l}\text { All manufacturing } \\
\text { industries }\end{array}$ & $\begin{array}{l}\text { Conventional } \\
\text { boiler use }\end{array}$ & $8.6 \%$ & $16.9 \%$ \\
\hline $\begin{array}{l}\text { Resistance heating and } \\
\text { melting }\end{array}$ & Glass & $\begin{array}{l}\text { Process } \\
\text { heating }\end{array}$ & $3.6 \%$ & $6.8 \%$ \\
\hline $\begin{array}{l}\text { Direct arc melting } \\
\text { Inon and steel }\end{array}$ & $\begin{array}{l}\text { Process } \\
\text { heating }\end{array}$ & $4.8 \%$ & $0.0 \%$ \\
\hline $\begin{array}{l}\text { Industrial process heat } \\
\text { pump }\end{array}$ & $\begin{array}{l}\text { Food, pulp and } \\
\text { paper, chemicals }\end{array}$ & $\begin{array}{l}\text { Process } \\
\text { heating }\end{array}$ & $1.3 \%$ & $10.0 \%$ \\
\hline
\end{tabular}

Industry total electricity use was then allocated on a state level based on the calculated proportion of combustion-related GHG emissions reported by manufacturing industries to the EPA Greenhouse Gas Reporting Program (GHGRP) in 2014 (U.S. Environmental Protection Agency 2016). It is assumed that combustion-related GHG emissions from these GHGRP reporters (facilities with annual emissions of over 25,000 metric tons) serve as appropriate proxies for energy use.

Limited data are available on hourly energy consumption by end use for industrial facilities; as a result, we leveraged industrial electricity load shapes developed for the Renewable Electricity Futures (REF) study (Mai et al. 2014).$^{60}$ These load shapes were based on current patterns in industrial electricity load and, therefore, do not capture any impacts that electrification would have on load shapes but rather assume that, in aggregate, incremental load associated with electrification is highly correlated with current load in the industrial sector. We convert the hourly loads from REF into an index of load and, using this index, disaggregate annual statelevel electricity estimates to hourly state level.

\footnotetext{
${ }^{60}$ For additional information on load data developed for the REF study, see http://www.nrel.gov/analysis/re futures/.
} 